NBER WORKING PAPER SERIES

\title{
COMPUTERIZING VAT INVOICES IN CHINA
}

\author{
Haichao Fan \\ Yu Liu \\ Nancy Qian \\ Jaya Wen
}

Working Paper 24414

http://www.nber.org/papers/w24414

\author{
NATIONAL BUREAU OF ECONOMIC RESEARCH \\ 1050 Massachusetts Avenue \\ Cambridge, MA 02138 \\ March 2018, Revised April 2020
}

Previously circulated as "The Effects of Computerizing VAT Invoices in China." We thank Esther Duflo, Gabrielle Fack, Hanming Fang, Lucie Gadenne, Mike Golosov, Jessica Leight, Magne Mostad, Dina Pomeranz, Stefanie Stantcheva and Daniel (Yi) Xu for their insights; and the participants of the MIT/Harvard Development Workshop, Northwestern Applied Micro Workshop, University of Zurich Macro and Development Seminar, MSU Development Workshop, University of Chicago Development Lunch, CEPR Development and Taxation Workshop, IMF and Atlanta Federal Reserve Bank's conference on the Chinese Economy, CEPR Development Workshop, M\&M Conference at the Chicago Federal Reserve Bank, Fudan University TED Conference, Peking University CCER Summer Institute, Lixin University Workshop on Public Finance, Shanghai Technical University Applied Workshop and Chicago Area Development Mini Conference for useful comments. We are grateful to Joris Mueller and Zhentao Jiang for excellent research assistance. All mistakes are our own.

NBER working papers are circulated for discussion and comment purposes. They have not been peer-reviewed or been subject to the review by the NBER Board of Directors that accompanies official NBER publications.

(C) 2018 by Haichao Fan, Yu Liu, Nancy Qian, and Jaya Wen. All rights reserved. Short sections of text, not to exceed two paragraphs, may be quoted without explicit permission provided that full credit, including $\odot$ notice, is given to the source. 
Computerizing VAT Invoices in China

Haichao Fan, Yu Liu, Nancy Qian, and Jaya Wen

NBER Working Paper No. 24414

March 2018, Revised April 2020

JEL No. H26,H32,O10

\section{ABSTRACT}

This paper documents that an increase in the enforcement of value-added tax (VAT) caused by the adoption of a new technology significantly increased VAT payments by large manufacturing firms in China. The reform contributed to $27.1 \%$ of VAT revenues and $12.9 \%$ of total government revenues in the five subsequent years. The main mechanism is likely to be a reduction in VAT deductions. The dynamic effects of the reform suggest that the rise in tax revenues is non-monotonic over time, with large short-run gains and smaller, though still positive, long-run gains. The reform also reduced firm revenues and inputs, and increased productivity.

Haichao Fan

School of Economics

Fudan University

fan_haichao@fudan.edu.cn

Yu Liu

Fudan University

Building 11, Room 107

220 Handan Road, Yangpu District

Shanghai, China, 200433

dav.yu.liu@gmail.com
Nancy Qian

MEDS

Kellogg SOM

Northwestern University

2001 Sheridan Rd.

Evanston, Il 60208

and NBER

nancy.qian@kellogg.northwestern.edu

Jaya Wen

1881 Oak Avenue 609W

Evanston, IL 60201

jaya.wen@gmail.com

A online appendix is available at http://www.nber.org/data-appendix/w24414 


\section{Introduction}

Limited administrative capacity is one of the key challenges facing governments of developing economies. There is much excitement among policymakers today that high-tech tools can help. This paper studies the effect of a new technology on tax compliance, a very important and relevant context since all governments tax and face the difficulty of enforcing payment. This is particularly challenging in low and middle income countries, which typically have less established systems for taxation. In such contexts, the Value Added Tax, VAT, is often one of the most important sources of tax revenues. ${ }^{1}$ VAT is generally levied as a fraction of the difference between eligible sales and input costs. This framework creates incentives for firms to understate sales and overstate inputs. In principle, since the sales of one firm become the inputs of another along the production chain, upstream and downstream firms are incentivized to check each other's tax evasion. However, in practice, firms can still evade because transactions are not linked in many countries (e.g., Pomeranz, 2015; Waseem, 2019). A common method for evasion in such contexts, and the one most relevant to our study, is to falsify invoices for eligible deductions.

This paper examines the impact of adopting a new technology - digital invoice encryption, which we often refer to as computerization for brevity - for VAT revenues in China. Encrypted invoices improved enforcement by increasing the difficulty of falsifying invoices: the invoices became physically more difficult to forge, and digitization reduced data entry costs and facilitated the linking of transactions. ${ }^{2}$ However, as VAT is the largest source of Chinese government revenue, peaking at 47.6\% in 2002, and China has

\footnotetext{
${ }^{1}$ For example, as a share of total government revenues, VAT accounts for $18.7 \%$ in Mexico, $9.5 \%$ in the Philippines and $17 \%$ in South Korea (OECD, 2016). The popularity of VAT is partly due to its perceived enforceability(Gordon and Li, 2009; Kleven, Kreiner, and Saez, 2016). Kopczuk and Slemrod (2006) argue that VAT is easier to enforce than sales tax, to which it is otherwise equivalent. Besley and Persson $(2009,2010)$ use the ratio of income tax revenues to GDP as a measure of bureaucratic capacity, with the underlying idea that VAT (as opposed to income tax) requires much less capacity to administer than other types of taxes.

${ }^{2}$ See Section 2 for a more detailed discussion.
} 
relatively high administrative capacity for a middle-income country, the benefits of the new technology are not obvious ex ante: i.e., enforcement through traditional means, such as manual audits, could be effective enough that the reform brings little improvement. ${ }^{3}$

The empirical analysis aims to address two questions. First, what is the effect of digital encryption on VAT in the short and longer run? Second, how did firms respond to the enforcement increase along dimensions other than tax payments?

Our study faces three main challenges. First, very little has been written about the operational details of the Chinese tax system. Second, dis-aggregated administrative VAT data for this period are not available to researchers. Finally, we face the challenge of establishing causality. Since we study a nationwide reform, a key difficulty is disentangling enforcement-driven changes in VAT revenue from changes from economic growth or other macroeconomic or policy changes.

The principal contribution of our paper is to address these challenges. To understand the practical realities of tax enforcement, we researched government documents and policy reports and conducted extensive field interviews with firm managers and tax officials at all levels of government, from the central tax office in Beijing to countylevel field officers in several provinces, as well as tax attorneys inside and outside of the government. The comprehensive background field work is important for our study because policy implementation in China can differ widely from white paper descriptions. To overcome the lack of dis-aggregated administrative tax data, we use the Annual Survey of Industrial Production, 1998-2007, which reports VAT payment, as well as the breakdown of gross VAT and deductibles. The latter is useful in providing evidence on the mechanism - i.e., showing how the reform increased VAT. Our main analysis uses a balanced panel of firms that exist throughout the period that we study.

\footnotetext{
${ }^{3}$ VAT and government revenues are reported by the China Tax Policy Department, Ministry of Finance 2007. In 2000, there were approximately 93,000 audits per year per province, which represent an average audit rate of $17.9 \%$. In comparison, the audit rate in the United States was 1.12 percent in the same year (Internal Revenue Service, 2001). See Section 2 for more discussion.
} 
To establish causality, we implement a difference-in-differences strategy. Prior to the reform, firms evaded VAT by understating sales and overstating deductibles with falsified invoices. The reform forced sellers to record transactions on a digital smart card and to give buyers encrypted invoices that were difficult to falsify. The increased difficulty in falsifying invoices should reduce the amount of false deductible claims. An important advantage for our study is that there were relatively few policy changes that affected VAT in the period that we study, which allows us to mitigate potentially confounding influences. ${ }^{4}$

Our empirical strategy exploits two sources of variation. First, we compare outcomes before and after the 2001 reform. Second, we exploit cross-sectional variation in the firms' non-deductible share: firms with higher non-deductible shares experience higher treatment intensity. ${ }^{5}$ Since evasion can confound the pre-reform non-deductible share measures from our firm survey data, we proxy for non-deductible share with sectorlevel measures calculated from the 1997 Chinese Input-Output Tables. These data are constructed using an independent data source by the National Statistics Bureau. The baseline estimates include firm fixed effects to account for all time-invariant differences across firms (e.g., firm size), and year fixed effects to account for all economy-wide changes over time (e.g., macroeconomic growth). To allow for firms of different sizes to evolve differentially over time, the baseline also controls for the interaction of the average firm size of each sector in the pre-reform period and the full set of year fixed effects.

We show that the reform significantly increased VAT on average. This is driven by a reduction in deductible inputs, which is consistent with the belief that the digital encryption of invoices significantly increased the difficulty of falsifying deductible claims. We show that there are no pre-trends and that VAT diverges between firms with high versus low non-deductible shares starting at the time of the reform. Taken literally,

\footnotetext{
${ }^{4}$ For example, there were several changes to VAT after our study period, for example, in 2009. See Section 2 for more discussion.

${ }^{5}$ See Section 3 for more discussion.
} 
the estimates imply that the reform contributed $27.1 \%$ of all VAT and $12.9 \%$ of all government revenue during 2002-2007. In other words, more than one-tenth of total government revenues for the world's sixth largest economy at the time is due to improved technology in recording VAT transactions.

There are several caveats to keep in mind. First, there may be cross-sector transactions such that improving enforcement in firms with high non-deductible shares will also improve the information chain in firms with low non-deductible shares (i.e., spillover effects) (e.g., Gadenne, Nandi, and Rathelot, 2019). This force will attenuate our estimates and cause them to understate the true increase in VAT from the reform. Second, the occurrence of the reform may have coincided with other events that can affect high nondeductible share sectors differently from low non-deductible share sectors. We are mostly concerned that China's entry into the World Trade Organization in 2001 may confound our estimates. To address this concern, we introduce a large number of sector-year specific controls for imports and exports. Finally, our reform occurs amidst the "enterprise reforms" (1998-2003) which partially privatized the historically state-controlled economy (Hsieh and Song, 2017). We address this by showing that our main results are robust when controlling for ownership-year fixed effects, and are qualitatively similar between a balanced panel of firms (that exist throughout the period) and the full sample of firms (that allows for firm entry and exit).

We conduct many additional sensitivity tests. For example, to check that our estimates are not confounded by spurious cross-sector changes over time, we conduct a placebo test, where we only examine exporters that are commonly thought of as "exempt" from VAT because of their eligibility for VAT rebates. Indeed, we find no effect on exporters. One may be concerned that despite the best efforts of government statisticians, the raw data used to generate the 1997 Chinese I-O tables are still confounded by evasion. To address this, we calculate the non-deductible shares using input-output tables from other countries and use these alternative measures as instrumental variables. 
The instrumented results are qualitatively similar.

Next, we examine the effect on other firm outcomes. We find that the reform reduced output, labor input, the share of deductible intermediate inputs and employment, and increased TFPR. In principle, these findings could be due to changes in firms' reporting behavior and/or economic behavior (i.e., real effects). In practice, it is difficult for a change in reporting to provide an internally consistent explanation for all of the observed changes in firm behavior. On the one hand, if firms misreport to evade VAT, then reported deductible intermediate inputs, for example, should increase, not decrease. On the other hand, if the reform forces previously evading firms to report more truthfully, then VAT eligible sales should increase instead of being unchanged. Moreover, the decline in labor inputs is difficult to explain with changes in reporting since it is not directly related to the calculation of VAT before or after the reform.

In light of the ostensibly conflicting results, we explore the possibility that our findings for output, inputs and productivity reflect real economic changes. In this supplementary exercise, we develop a simple theoretical framework to show that all of our empirical findings follow from standard assumptions. The model also makes several empirically testable predictions for the dynamic effects of an increase in taxation for firms. For example, it predicts that the effect of the reform on VAT is non-monotonic over time: it will first increase, then decrease slightly, but still be higher than prior to the reform. We show that the dynamic effects of the reform are consistent with these predictions. While we cannot conclusively rule out all alternative explanations, the empirical findings and simple model, taken together, are consistent with the reform causing firms to change their economic behavior in the medium/long run.

For policymakers, our results provide several important takeaways. First, high-tech tools can dramatically boost tax revenues, even if the government has reasonable capacity for manual audits such as in China. Second, the dynamic effects provide suggestive evidence that tax revenue gains may be slightly lower in the long run than the short run, 
but will remain positive. In other words, even with real economic responses to the tax increase, tax revenue gains are likely to stay positive, at least in the Chinese context.

Our study contributes to several literatures. In studying how large Chinese manufacturing firms respond to VAT incentives, our study is most closely connected to Chen, Liu, Serrato, and Xu (2017), which examines R\&D expenditures of large manufacturing firms; and Liu and Lu (2015), Liu and Mao (2019) and Cai and Harrison (2011), which examine firm investment. These studies exploit policy changes that occur after our period of study. ${ }^{6}$ In examining VAT in a middle-income economy, our study is most similar to Pomeranz (2015), which conducts a large randomized experiment in Chile to show that third-party information improves VAT enforcement; and Gadenne, Nandi, and Rathelot (2019), which uses linked transaction-level data from Bengal to study supply chain responses to increased taxation. We complement these studies by examining a very different context and providing evidence on the dynamic effects. Most existing studies focus on short-run effects and do not find real effects. ${ }^{7}$ An exception is Benzarti, Carloni, Harju, and Kosonen (2017), which finds that VAT has short- and long-run effects on prices in Finland. Our finding that firms downsize in response to value-added taxation is consistent with a recent study by Harju, Matikka, and Rauhanen (2015), which finds that VAT reduces the growth of small firms in Finland.

The large tax revenue gains from computerization illustrate the power of high-tech tools for improving state capacity and provide support for recent studies such as Barnwal (2016), Banerjee, Duflo, and Glennerster (2008), Duflo, Hanna, and Ryan (2012) and Muralidharan, Niehaus, and Sukhtankar (2016) with data and a policy reform from a very different context.

\footnotetext{
${ }^{6}$ The reform that is the focus of the latter two studies is piloted in select provinces during our study period. We discuss these in more detail in the robustness section. Also, see the recent study by Bai and Liu (2017).

${ }^{7}$ For studies of other types of taxes in developing countries, see, for example, Naritomi (2015) or Mittal and Mahajan (2017). See Keen and Lockwood (2010) for an overview of the VAT literature, and the review article by Saez, Slemrod, and Giertz (2012) for a review of empirical estimates of responses to taxes. Also see, for example, Kleven and Waseem (2013) and Piketty, Saez, and Stantcheva (2014), which study income tax in Pakistan and the United States, respectively.
} 
This paper is organized as follows. Section 2 discusses the relevant institutional background. Section 3 presents the empirical strategy. Section 4 describes the data. Section 5 presents the main results. Section 6 interprets the results and examines the dynamic effects. Section 7 concludes.

\section{Background}

The Chinese government introduced VAT, which is administered by the central government, in its modern form in 1994 in what is commonly known as the first phase of the Golden Tax Project. By 2002, VAT had grown to be the largest source of tax revenue and was $47.6 \%$ of total government revenues (National Bureau of Statistics, 2003). ${ }^{8}$ All formal manufacturing firms were required to register within the VAT system, either as a "small VAT taxpayer" or a "general VAT taxpayer". Within the manufacturing sector, firms with less than one million RMB (120,772 USD) in annual sales were categorized as "small", and larger firms were categorized as "general" (Ministry of Finance, 1993). ${ }^{9}$ Because our dataset contains only firms much larger than this cutoff (i.e., annual revenues exceeding five million RMB, or 603,864 USD), we focus the rest of our discussion on general VAT taxpayers.

For general VAT taxpayers, the final VAT bill is $17 \%$ of the VAT tax base, which equals the difference between total VAT eligible sales and total eligible input deductions. ${ }^{10}$ There were no major changes in the VAT formula during the period of our study.

Chinese tax law is precise about which inputs are deductible and the rate at which they may be deducted (Ministry of Finance, 1993). In our study period, full deduc-

\footnotetext{
${ }^{8}$ See the "Regulations of the People's Republic of China on Value-Added Tax" (State Council, 1993) and the "Detailed Rules for the Implementation of the Regulations of the People's Republic of China on Value-Added Tax" (Ministry of Finance, 1993).

${ }^{9}$ We use the 1 USD $=8.28 \mathrm{RMB}$ conversion rate from 2000 in this paper.

${ }^{10} \mathrm{An}$ exception of a reduced rate of $13 \%$ was made for basic staples or household necessities such as food, fuel, electricity, books, newspapers and magazines, and primary agricultural products (State Council, 1993). This does not affect our study, which examines large manufacturing firms.
} 
tions were awarded for purchases of manufactured inputs, repair inputs, retail inputs and wholesale inputs. Partial deductions were given for agricultural goods (13\%), transportation costs $(7 \%)$ and procured waste goods (10\%). To obtain deductions, firms provide corresponding official receipts for each transaction. ${ }^{11}$ Unlike many other countries with VAT, no deductions were given for labor costs, fixed asset purchases, capital depreciation, abnormal losses, rent, fringe benefits, interests from bank loans, and operating expenses (overhead). ${ }^{12}$ For any deductible imported inputs, firms could deduct purchases using VAT completion receipts issued by the customs office (State Council, 1993). Exports are partially exempt from VAT due to rebates that vary by sector and year.

A typical VAT-relevant transaction is a firm-to-firm sale of some input. An official invoice with carbon copies is generated: one copy for the buying firm and the other one for the selling firm. Registered firms can purchase these invoices from the tax office at any time. Firms pay VAT and obtain deductions monthly. Each month, someone from the firm would go to the local tax office and give the tax official all of the invoices for her VAT eligible sales from the past month. These are used to calculate her VAT obligations, which she will need to pay on the same day. During the same visit, she will give the tax official all of the invoices for her VAT eligible deductibles. Her deductions are calculated and paid to her on the same day.

In the pre-computerization period, VAT fraud was prevalent ( $\mathrm{Lu}, 1997 ; \mathrm{Jin}, 2002){ }^{13}$ Enforcement faced two closely connected difficulties. First, VAT invoices were handwritten and lacked effective anti-counterfeit technology. Second, cross-checking invoices, especially across locations, was prohibitively costly with manual auditing. As a result, firms could fabricate input purchase invoices and be fairly certain that they would not

\footnotetext{
${ }^{11}$ Note that transactions of partially deductible goods do not use VAT invoices. They were not affected by the reform that we study.

${ }^{12}$ The Appendix provides a detailed list of deductible and non-deductible items.

${ }^{13}$ Between January and September of 2001, there were in total 10,041 criminal cases on taxes nationally in China and $59 \%$ of these cases were related to over-reporting input VAT (page 632 of China's Tax Audit Yearbook, 2003).
} 
be caught. Similarly, firms could use real invoices of canceled transactions to file for deductions, because tax authorities would not know that the other party had never filed the sales.

Although the law stipulated financial and criminal punishments for VAT evasion, firms were, in practice, rarely subject to those penalties. This lax behavior on the part of the authorities was largely due to the inability of the auditor to conclusively prove evasion or estimate the amount of evasion without a clear paper trail.

According to interviews with tax officials, they targeted inspections, visits and audits at firms and sectors with a high level of deductibles as share of sales. This insight is part of the motivation for our empirical strategy, which we discuss later in the paper. This rule-of-thumb targeting did not change after computerization. ${ }^{14}$

\subsection{Reform}

\section{Encrypted Invoices}

The goal of the second phase of the Golden Tax Project in 2000 was to address these two central problems of VAT enforcement with a fully digitized invoice system coupled with a national database of firm VAT filings. The two most important components of this reform were: 1) replacing hand-written invoices with digitally encrypted invoices, and 2) digitally linking transactions. ${ }^{15}$ Firms were required to insert a special-purpose IC smart card in their computers. The IC card contained seven key pieces of encrypted transaction information (invoice ID, invoice code, invoice date, buyer's tax ID, seller's tax ID, value, and VAT) into an 84-digit code. ${ }^{16}$ During a transaction, basic information

\footnotetext{
${ }^{14}$ To the best of our knowledge, there are no disaggregated data on audits available to researchers. See the Appendix for a discussion about the aggregate audit data.

${ }^{15}$ See Jin (2002).

${ }^{16}$ The technology has continuously improved. For example, in later years, the government extended the 84-digit code into a 108-digit code. In 2011, another improvement permitted the encryption of Chinese characters as well as numerals, so the government added additional information to deduction invoices in a few designated sectors (e.g., gold, gasoline, rare earth, etc.) in three provinces (Shanghai, Shaanxi, and Shenzhen). The information includes the seller's name, the buyer's name, the product name and the quantity sold.
} 
would be stored into the IC card, and the seller would print the deductible amount on an encrypted paper invoice for the buyer. ${ }^{17}$

After the reform, firms continued to pay VAT during monthly visits to State Administration of Tax (SAT) offices. They presented their IC cards as well as printed copies of the encrypted deduction invoices. As before, the net payment is calculated and made at the tax office the same day of the visit. In principle, the deduction invoices were supposed to be cross-checked with a national database with the transactions that are downloaded from all IC cards in the nation, effectively linking all transactions. We discuss this in more detail later in this section when we discuss the timing of the reform.

Policy makers claim that the technology has had a remarkable deterrence effect on VAT frauds in China, mainly by reducing exaggerated deductions. For example, in February 2001, the fraud rate of input VAT invoices, which is measured as the number of invoices determined to be "problematic" over the total number of invoices audited, was $8.51 \%$. By August 2002, the fraud rate dropped to 0.062\% (Jin, 2002). On January 20, 2003, the former deputy head of SAT stated that the over-invoicing problem had been basically resolved. ${ }^{18}$ Beyond tax officials, it is widely believed by firms and other policy makers that fake invoices have almost completely disappeared.

\section{Timing}

The encryption of invoices took some time to implement. Starting from January 1, 2000, invoices of transactions exceeding 100,000 RMB (12,077 USD) were printed out using the new encryption software. Handwritten invoices for these large transactions were banned at the end of 2001. Large transactions are very common for the large manufacturing firms that we study. Thus, we interpret 2002 as the first year that the reform became relevant (State Administration of Taxation, 2000). By all accounts, the implementation of encrypted invoices was carried out according to plan.

\footnotetext{
${ }^{17}$ Appendix Figures A.2 and A.3 show the paper invoices before and after the digital encryption.

${ }^{18}$ See China Tax Audit Yearbook Committee (2004).
} 
Evidence on the timing for linking transactions is more ambiguous. Interviews with province-level officials in two provinces indicate that they were able to enforce compliance with the nationally linked database as early as 2001, but officials from other provinces and the central tax office were unwilling to confirm when they began to use the linked database to enforce compliance (or if they ever did within the period that we study).

We therefore interpret the reform to increase compliance in the following way. Starting in 2001, the introduction of digitally encrypted invoices made it harder to falsify transaction amounts. This difficulty further increases if and when the nationally linked database is used to enforce compliance, the timing of which may endogenously vary across provinces. Thus, our empirical strategy will not exploit cross-province variation in linking invoices. Instead, we interpret the 2001 reform as a nation-wide reform that increased the difficulty of falsifying invoices, and show that our results are robust to controlling for province-year fixed effects, which accounts for the potentially endogenous introduction of using the linked invoices to enforce compliance.

The reform made VAT evasion much costlier, but some loopholes remained. According to our interviews with tax officials, the main methods of evading VAT after the reform are the following. First, in times and places where transactions were not systematically linked, firms could still understate sales by simply not producing a sales receipt (i.e., no record on the IC card). This needs to be done carefully since large changes in sales can trigger an audit. The scope of such evasion is also limited because only a purchaser not intending to file deductions would be willing to forgo the receipt. Second, a subset of receipts (including procurement receipts for agricultural goods, customs VAT completion receipts, transportation receipts, and waste goods) were never digitally encrypted as part of the reform. Thus, it was still possible to falsify these invoices. Third, firms can buy genuine VAT invoices from the black market because some final customers do not claim the VAT input invoices. Finally, firms in the entire value chain could opt for off-book cash transactions. This is difficult because it requires coordination across many firms. 
Furthermore, by switching to cash transactions, firms would record a drop in sales, which can trigger audits. ${ }^{19}$ We will keep these caveats in mind when we interpret the empirical results and motivate the robustness exercises.

\subsection{Imports and Exports}

The VAT payment rules that we have described thus far applies to almost all goods in China. Two notable special cases are imports and exports (State Council, 1993). Import tariffs existed in China throughout this period, and those tariffs were deductible in the same manner as the original input value. Exports were awarded VAT rebates throughout the period of our study. Unlike many other countries with VAT, Chinese export rebates are typically less than the total sum owed - i.e., firms pay some VAT on exports (Chandra and Long, 2013). Both import tariffs and export rebates vary across sectors (products) and over time. We will pay special attention to this issue in the robustness exercises.

\subsection{Other Policy Changes}

The main policy change that could confound our study was China's entry to the WTO in 2001. Our empirical approach, which we describe in Section 3, is a difference-indifferences strategy that compares firm outcomes before and after 2001, across firms that had high and low exposure to the increase in enforcement. Therefore, a possible threat to our identification strategy is that WTO-led changes in tariffs and rebates differentially affected high- and low-treatment intensity sectors after 2001. We address this possibility later in the paper by explicitly controlling for rebates and tariffs for each sector and year.

Another important policy for our context is the privatization of state-owned firms, often referred to as "enterprise reforms", which took place during 1998-2003. The manufacturing sector transitioned from nearly entirely publicly (state) owned to partly privately

\footnotetext{
${ }^{19}$ The government aimed to resolve these remaining loopholes through an improved tax enforcement technology. The third phase of the Golden Tax Project was piloted in Chongqing in 2013 and applied nationwide in 2016. It is outside of the scope of our study.
} 
(not state) owned and some state firms closed down entirely. ${ }^{20}$ To avoid potentially confounding effects from firm entries and exits, our main analysis focuses on a panel of firms that exist throughout the period of our study. We will also later show that the results are qualitatively similar if we allow for entry and exit and expand the sample to all manufacturing firms, as well as control for ownership-year fixed effects in the robustness exercises.

In the years after computerization, several other potentially relevant policy changes took place. First, in 2004, the central government changed how it split the burden of VAT export rebates with local governments (Chandra and Long, 2013; Bai and Liu, 2017). Another potentially relevant policy change was the abolition of agricultural taxes in 2005, which Chen (2017) argues to have increased the enforcement of other taxes to compensate for lost revenues. Finally, VAT policies were amended in 2009. Though this policy change falls outside our time frame (Cai and Harrison, 2011; Liu and Mao, 2019; Liu and Lu, 2015), some of the changes were piloted in three provinces (Liaoning, Jilin, and Heilongjiang) starting in 2004. It is important to note that a broader set of changes were implemented to VAT after 2009, but no during the period that we study.

We will investigate the robustness of our results to each of these policy changes after the main results.

\section{Empirical Strategy}

We exploit two sources of variation: time variation in the introduction of computerization and encrypted invoices in 2001, and cross-sector variation in the intensity of the treatment effect. Broadly speaking, the reform applied the new technology similarly for all firms (see Section 2). However, the degree of evasion prior to the reform varied across firms, which introduces cross-sectional variation in reform intensity. According to tax officials, the firms that were the most likely to evade prior to the reform were those with a high

\footnotetext{
${ }^{20}$ See, for example, Hsieh and Song (2017) for a detailed discussion.
} 
level of non-deductible inputs as a share of sales. This was ostensibly for two reasons. First, they had few legitimate deductibles with which to lower VAT obligations (as a share of sales). Second and perhaps more importantly, these firms were unlikely to have been inspected or audited by tax officials, who focused their attention on firms and sectors with a high level of deductibles as a share of sales. Thus, the reform intensity was higher - i.e., it increased compliance more - for firms with a higher share of non-deductibles.

Note that because the pre-reform reported VAT deductions in our firm data may be confounded by evasion, the explanatory variable uses data from the 1997 Chinese Input-Output table, which is available at the sector level. These data are constructed by the National Bureau of Statistics using a survey that is independent of the firm survey we examine.

The cross-sectional measure of intensity, non-deductible input share, is denoted as $\widetilde{N D} S_{s}:$

$$
\widetilde{N D} S_{s}=\left(\frac{\text { NonDeductible Inputs }}{\text { Total Sales }}\right)_{s}
$$

The second term, $\left(\frac{\text { NonDeductible Inputs }}{\text { Total Sales }}\right)_{s}$, is the ratio of the sum of non-deductible inputs to total output in sector $s$. To construct NDS by sector, we map each sector in the input-output tables into two groups, deductible or non-deductible, according to Chinese tax law. In practice, we consider inputs from agricultural, mining, and manufacturing industries to be materials, and thus deductible. We treat inputs from service industries, overhead, labor inputs, and value-added to be non-deductible. ${ }^{21}$

\footnotetext{
${ }^{21}$ In a standard input-output table, the sum of all input values should be equal to the value of output. Therefore, to obtain the final measure, we can equivalently sum the fractions of inputs from deductible industries to obtain a single fraction for each industry that represents the share of inputs deductible under Chinese VAT rules. This object can be characterized by the following equation, where $D$ represents the set of deductible industries:

$$
\widetilde{N D S_{s}}=1-\sum_{d \in D} \text { Input fraction }_{s d}
$$

Appendix Table A.1 lists the fifty sectors with the highest and lowest values for $\widetilde{N D} S_{s}$.
} 
The baseline estimating equation can be written as the following:

$$
V A T_{i s t}=\alpha+\beta \widetilde{N D} S_{s} \times \text { Post }_{t}+\Gamma X_{i s t}+\tau_{t}+\phi_{i}+\epsilon_{i s t} .
$$

VAT paid by firm $i$, in sector $s$, and year $t, V A T_{i s t}$, is a function of the interaction of a dummy which takes the value of one if it is 2002 or later, and the measure of intensity at the sector level, $\widetilde{N D} S_{s}$; firm fixed effects, $\phi_{i}$; and year fixed effects, $\tau_{t}$. We choose 2002 as the start of the post-period because hand-written invoices were not banned until the end of 2001. ${ }^{22}$ The standard errors are clustered at the sector level. Note that sector fixed effects are absorbed by firm fixed effects.

$X_{i s t}$ is a vector of controls. In the baseline, the only additional controls are the interactions of year fixed effects and average pre-reform firm size at the sector level (i.e., average annual sales in each sector during 1998-2000 interacted with year fixed effects). This is motivated by recent findings that compliance to tax policy varies by firm size (Bachas and Jensen, 2017; Kleven, Kreiner, and Saez, 2016). ${ }^{23}$

We are interested in the estimate of $\beta$. If the reform increased compliance and VAT, then $\beta>0$.

Our DiD strategy assumes parallel trends - i.e., absent the reform, the outcomes of interest across sectors with different non-deductible shares would have evolved along parallel trends (conditional on the controls). We will provide support for this assumption by conducting the standard pre-trend analysis, as well as a number of robustness tests to address potential omitted variable concerns.

We acknowledge two caveats to our identification strategy. The first is that we do not have a pure control group. Sectors with low non-deductible shares may still have evaded VAT prior to the reform (albeit less than sectors with higher non-deductible shares). Thus, the reform will also increase their VAT compliance (though less than for

\footnotetext{
${ }^{22}$ In Section 6, we separately consider firm responses in 2001-2002.

${ }^{23}$ The estimates are nearly identical if we control for average annual sales in each firm during 1998-2000 interacted with year fixed effects. They are available upon request.
} 
sectors with higher non-deductible shares). The second caveat arises from the presence of cross-sector transactions. This is particularly relevant when the transactions become linked: higher compliance in sectors with high non-deductible shares will lead to higher compliance in sectors with low non-deductible shares. Both caveats will lead to our results under-estimating the effect of the reform on increasing VAT. ${ }^{24}$

Another issue is the measurement of $\widetilde{N D} S_{s}$. One might be concerned that despite the best effort of the National Bureau of Statistics, the raw data used to generate the 1997 Chinese I-O tables are confounded by evasion. To address this, we conduct a robustness check where we alternatively construct the measure using data from U.S. input-output tables, as well as input-output tables from Mexico and South Korea. We then use these alternative measures as instrumental variables for our main measure. We will discuss this in more detail when we present the results in the robustness section.

\section{Data}

Our main sample is a balanced panel of firms for the years 1998-2007 constructed from China's Annual Survey of Industrial Production. These data are collected by the National Bureau of Statistics and are often referred to as the "Census of Manufacturing Firms". The unit of observation is the firm. Subsidiaries are coded as separate entities as long as they are unique legal units. ${ }^{25}$ The inclusion and exclusion criteria for non-stateowned firms are asymmetric. The dataset includes all state-owned manufacturing firms (regardless of size) and non-state manufacturing firms with sales greater than five million RMB (603,865 USD). These data have been used by several recent studies. The most well-known is probably Hsieh and Klenow (2009), which used all of the years available when their paper was written, 1998-2005.

\footnotetext{
${ }^{24}$ Note that an ostensibly reasonable alternative strategy is to use exporting sectors, which are commonly thought of as "exempt" to VAT, as a control group. However, in practice, the VAT rebates for exporting sectors vary over time and across sectors, and there is no one sector that is always VAT exempt.

${ }^{25}$ For regulatory reasons, most subsidiaries are separate legal entities in China.
} 
The five-million RMB revenue threshold for non-state-owned firms is not systematically imposed: we observe non-state-owned firms below this threshold (with no apparent pattern in firm attributes). To avoid selective sampling, we impose a uniform cutoff and drop all observations with less than five million RMB (603,865 USD) in revenues.

The data contain a rich set of variables. Most importantly, firms report VAT payment, and also gross VAT and VAT deductions. The availability of the two component measures of VAT is useful in that it allows us to examine the mechanisms through which the reform improves enforcement. It is important to note that the VAT payment variable is inclusive of rebates, like those awarded for exports. We will discuss and motivate other variables as they become relevant.

All of the values in the paper are reported in real terms. ${ }^{26}$ The main sample is a nearly balanced panel of 180,148 firm-year observations that operate from 1998-2007.27 To avoid outlier-driven results, our sample excludes observations with the top and bottom $1 \%$ values of VAT and sales each year. ${ }^{28}$ We use 4-digit Chinese Industry Classification sector definitions.

We use the 1997 Chinese Input-Output (I-O) Table obtained from the China's National Bureau of Statistics (1999) to compute a sector-level non-deductible share. The I-O Tables report the exact share of inputs by sector required in order to deliver one dollar of output. We use the 1997 tables so that the measures are not outcomes of the reform. The data used to create the Chinese I-O tables were independently collected by the National Bureau of Statistics (NBS). To the best of our knowledge, they are unrelated to either the firm data or the State Administration of Taxation.

\footnotetext{
${ }^{26}$ We use deflators provided by the Penn World Tables. To the extent that one is concerned about region-specific changes in prices, we show that our results are robust to controlling for province-year fixed effects in the robustness section.

${ }^{27}$ Note that the panel is not perfectly balanced because some variables are missing for some years. All firms in the sample have non-missing values for the key variables for at least nine of the ten years that we study.

${ }^{28}$ The results are qualitatively similar without dropping the outliers, but slightly less precise. They are available upon request.
} 


\subsection{Descriptive Statistics}

To illustrate the variation behind our empirical strategy, Figure 1 plots average VAT over time for firms with above and below the sample median of non-deductible share. Since average VAT payments are much higher from the high share group (2.19 million RMB, or $264,492.75$ USD) than the low share group (1.88 million RMB, or 227,053 USD), we normalized the data to the 1998 mean for both groups to better visually compare the trends over time. Consistent with macro-economic growth, the figure shows that VAT increased throughout the entire sample period for both groups. Importantly, the increase was similar between the two groups prior to the reform, and diverged after 2001, with the high-share group experiencing a larger increase. Conceptually, our empirical strategy will compare the average difference between the two lines after the reform to the average difference before the reform. (In practice, the regressions will exploit all of the variation in non-deductible share instead of breaking it up into two groups). The similarity in the pre-reform increase supports the parallel trends assumption of the DiD strategy. The timing of the divergence supports our interpretation that the second difference captures the effects of computerization rather than other changes that occurred before or afterwards.

\subsection{Correlates of Non-Deductible Share}

Since non-deductible share is not randomly assigned, one of the main concerns for our identification strategy is omitted variables. Table 1 documents the differences between high and low-share sectors by estimating the correlation coefficient of non-deductible share and a number of pre-reform firm characteristics averaged at the sector level. For brevity, we focus on variables which we later examine as outcomes. These cross-sector correlation coefficients show that, on average, firms in sectors with high non-deductible shares pay higher VAT, pay higher VAT as a share of sales, and pay fewer VAT deductions. On average, firms in high non-deductible share sectors are more productive, have 
lower sales, fewer intermediate inputs, a lower ratio of intermediate inputs to sales, and a lower ratio of deductible inputs to sales.

\section{Average Effect of the Reform}

\section{$5.1 \quad$ VAT}

Table 2 examines the effect of computerization on VAT. The sample means of the dependent variables are stated at the top of the table. In this subsection, we focus on the OLS estimates in Panel A. We will discuss Panels B and C in subsection 5.2.3. Column (1) shows that the effect on VAT eligible sales (gross VAT) is negative, but statistically indistinguishable from zero. Column (2) examines deductions, and shows that the reform reduces deductions. The estimate is statistically significant at the $5 \%$ level and is larger in magnitude than the estimated reduction in gross VAT in column (1). The reform, on average, reduced VAT deductions by 5,312×1,000 RMB (5.312 million RMB, or 641,546 USD) for a firm in a sector with no deductibles (i.e., the non-deductible share is $100 \%$ of sales) relative to a firm in a sector where all sales are deductible (i.e., the non-deductible share is $0 \%$ of sales). In terms of magnitudes, a back of the envelope calculation shows that a firm with the sample mean non-deductible share of 0.40 would have experienced a $21.92 \%$ decline in VAT deductions after computerization. ${ }^{29}$

Column (3) shows that the reform increased VAT payment, which is unsurprising, since the effect on reducing deductions is larger than the effect on sales. The estimate is statistically significant at the $5 \%$ level. In terms of magnitudes, this coefficient implies that the treatment contributed to $27.11 \%$ of total VAT revenues and $12.9 \%$ of total Chinese government revenues in the period after 2002 until $2007 .{ }^{30}$

The results show that the reform increased VAT paid by firms. Moreover, the fact that

\footnotetext{
${ }^{29}$ See Appendix Section D for the calculation.

${ }^{30}$ See Appendix Section D for the calculation.
} 
the increase is driven by a decline in deductions is consistent with conventional wisdom that the reform mainly impacted firms by removing their ability to falsify invoices for deductions.

Column (4) examines VAT as a share of sales. If VAT payments increase because of a change in enforcement, we may expect it to increase as a share of sales. Indeed, the coefficient is positive and statistically significant at the $10 \%$ level. Note that the denominator here is total firm revenues, which is reported in a different module of the firm survey. We use this measure instead of VAT eligible sales because the latter could be affected by the reform if the reform increased the difficulty of understating gross VAT. However, given that we find that the reform had no effect on the latter, the distinction is not very important in practice.

\subsection{Robustness and Sensitivity Analysis}

\subsubsection{Pre-trend Analysis}

To investigate the validity of the parallel-trends assumption, we re-estimate the baseline equation except that we replace the interaction term $\widetilde{N D} S_{s} \times$ Post $_{t}$ with the interaction of $\widetilde{N D} S_{s}$ and each year dummy variable. We plot the interaction coefficients in Figure 2. It shows no pre-trend. The coefficients for the years prior to the reform are zero. The effect of the reform begins after 2001. This figure is consistent with the raw data illustrated earlier in Figure 1.

\subsubsection{Additional Controls}

Next, we consider potential omitted variables. As we discussed earlier, the main confounding event was China's entry into the WTO in 2001 and the ensuing changes in tariffs. This will confound our estimates if entry differentially changed the effective VAT rate according to non-deductible share. (The economy-wide effect of entry into the WTO is already controlled for by the year fixed effects). To investigate this possibility, we con- 
struct measures of import tariffs, export VAT rebates and export duties for each sector and year. ${ }^{31}$ Table 3 column (2) shows that the results are very similar in magnitude to the baseline, which is restated in column (1) for comparison. Note that the number of observations changes slightly because we are unable to obtain data on tariffs for all sector-years.

Related to this idea, we address sector-specific changes in exposure to changes in the export market by controlling for average export growth rates in each sector in the pre-reform years interacted with year fixed effects. The coefficient in column (3) is very similar to the baseline.

Column (4) shows that our estimates are very similar if we control for the competitiveness of the sector measured using the Herfindahl-Hirschman Index (HHI) variable interacted with year fixed effects.

To address the possibility that there are province-specific policy changes or differences in the implementation of the reform (e.g., some provinces used the linked transaction database before others), or changes in province-specific economic conditions, we control for province-year fixed effects. For example, Chen (2017) argued that the abolition of agricultural taxes in 2005 led tax authorities to supplement their lost income with other tax sources such as VAT. Although the reform was a national level policy change, the extent to which provincial governments relied on agricultural taxes varied. Provinceyear fixed effects control for the potentially confounding influences of this reform to the extent that the revenue loss differed across provinces. Similarly, recall that we deflate the main dataset with a national deflator. But one may be concerned that prices change differentially across provinces. Column (5) shows that our results are very robust to the inclusion of province-year fixed effects.

Another way to address the possible confounding influences of the abolition of Agricultural Taxes in 2005 is to control for the extent to which each county relied on agricul-

\footnotetext{
${ }^{31}$ Rebate data are from (Garred, 2016). We use the method presented in Fan, Li, and Yeaple (2015); Fan, Gao, Li, and Luong (2018) to obtain output and input tariffs.
} 
tural taxes as a source of revenue before the VAT reform. We use the county-level share of government revenue from agricultural taxes in 2000, and then control for this crosssectional measure interacted with year fixed effects. The results from this regression are reported in Column (6), and they are similar in magnitude and precision to the baseline.

One may also be concerned that the main results spuriously capture differences in global demand or supply shocks between sectors with high and low non-deductible shares. We address this concern by controlling for the total amount of imports and exports in each sector and year. ${ }^{32}$ The estimate in column (7) is very robust to these additional controls.

As we discussed in Section 2, further changes in VAT policy made in 2009 (increasing the number of inputs that qualified for deductions) were piloted in three northeastern provinces (Liaoning, Heilongjiang and Jilin) starting in 2004 (Cai and Harrison, 2011; Liu and Mao, 2019; Liu and Lu, 2015). To investigate whether our main results are confounded by the pilot, we omit all observations from these provinces starting in 2004 . Column (8) of Table 3 shows that the resulting estimate is very similar to the baseline.

Finally, in column (9), we control for ownership interacted with year fixed effects. This addresses the possibility that privately owned firms and state-owned firms may have evolved differently over time or that state-owned firms were affected by the reform differently from privately owned firms. For example, the enterprise reforms are usually considered to have taken place during 1998-2003. During this period, many state-owned firms were restructured, shut down, or privatized (e.g., Hsieh and Song, 2017). One may naturally wonder whether such restructuring confound the VAT reform that we study. Our estimates when controlling for ownership-year fixed effects are very similar to the baseline.

\footnotetext{
${ }^{32}$ These data are reported by China's General Administration of Customs, 1998-2007.
} 


\subsubsection{Measurement Error}

To address the possibility that the non-deductible share calculated using our firm survey prior to the reform may capture evasion in addition to the true level of non-deductible share, we use 1997 Chinese I-O Tables to construct proxy measures. To the best of our knowledge, the latter dataset is constructed from an independent data source. However, the lack of transparency in how the I-O tables are generated leaves open the concern that they may nevertheless still be confounded by evasion in the pre-reform years. This is a concern for our analysis if the evasion captured in the data changes the cross-sector rank in terms of non-deductible shares. This seems unlikely ex ante. However, to be cautious, we address this issue by instrumenting for the OLS measure with non-deductible shares calculated from 2007 U.S. Input-Output Tables. U.S. non-deductible shares across sectors will not reflect evasion under pre-period Chinese tax rules.

Table 2 Panel $\mathrm{C}$ presents the reduced form estimates. Panel B shows the 2SLS estimates and the first stage Kleibergen-Paap F-statistic, 26.65. The instrumented estimates are similar or larger in magnitude than the OLS estimates in Panel A, which goes against the concern that the main OLS results are driven by measurement error in the explanatory variable. The statistical precision varies across columns.

One concern in using the U.S. 2007 I-O tables to construct the instruments is that the former may be influenced by the reform that we study via trade connections between the United States and China. ${ }^{33}$ We address this issue in two ways. First, by showing that 2SLS results are robust when we exclude sectors for which trade exposure, measured as the share of U.S. imports or exports from/to China, is high. Second, we also show that using the I-O tables of Mexico and South Korea to construct the instruments produces similar results. See the Appendix for these results.

\footnotetext{
${ }^{33}$ Earlier years of U.S. I-O tables are difficult to harmonize into Chinese I-O table categories.
} 


\subsection{Additional Results for VAT}

\subsubsection{Spillover Effects in Enforcement}

Here, we consider whether improved enforcement of VAT had positive spillover effects in the enforcement of other types of taxes. We examine corporate income tax payments, which are also reported in our survey data. Table 4, column (1) shows that the interaction coefficients are positive but statistically insignificant. Thus, there is no evidence of positive spillovers, which is perhaps unsurprising if the main mechanism for increased VAT is the reduction of false VAT deduction invoices.

The result on corporate tax is also interesting for another reason - it provides evidence against the concern that our main finding that computerization increased VAT is confounded by general improvements/changes in the tax system, or better enforcement of other types of taxes.

\subsubsection{Heterogeneous Effects for Exporters and Importers}

Next, we divide the sample according to export shares and imported input shares. This dimension of heterogeneity is interesting given the importance of trade to China's manufacturing sector. We divide the sample according to whether export or import shares in the sector are lesser or greater than the sample median in 1998-2000. ${ }^{34}$ Columns (2) and (3) test whether the treatment effect differed by the pre-period sectoral export share. Note that the sample median export share is zero, which is why the subsample in Table 4 column (2) is much larger than that of column (3). In columns (4) and (5), we test whether the treatment effect differed by the pre-period sectoral imported input share. The estimates show that the reform increased VAT more for firms in sectors that exported and imported less. The p-values at the bottom of the table show that the estimates from the different sub-samples are almost statistically different at conventional

\footnotetext{
${ }^{34}$ Export shares are calculated using our data. Imported input shares are calculated using Chinese Customs Administration data.
} 
levels. The results are consistent with the presence of significant export rebates for VAT. It is also reassuring because it goes against the concern that our findings are confounded by global demand shocks that are spuriously correlated with the non-deductible share of sectors. If that were the case, omitting the sectors that trade more with other countries should weaken our results.

\subsubsection{Heterogeneous Effects According to Distance from End Consumers}

Another interesting dimension of heterogeneity to examine is the distance to the end consumer. Studies such as Pomeranz (2015) have found that in Chile, the strength of enforcement weakens towards the end consumer because the end consumer is not incentivized to ask for receipts. ${ }^{35}$ Unlike the Chilean context, the Chinese government incentivizes end consumers to ask for receipts by making each official receipt a lottery ticket. ${ }^{36}$ However, it is widely believed that retail sales tax in China is not well enforced. The p-value at the bottom of Table 4 columns (6) and (7) is close to one, which shows that the effect of computerization is very similar for firms that are closer versus further away from the final consumer. These results should be interpreted cautiously. Because our sample contains large manufacturing firms, we do not observe firms at the very top or bottom of the supply chain.

\subsubsection{Heterogeneous Effects by Ownership}

We use the official ownership registration definition to define two key categories of ownership: state-owned firms and private firms. We categorize official state-owned firms, collective ventures, and joint ventures as state-owned firms. We categorize private enterprises and limited-liability companies as private firms. The estimates in Table 4 columns (8) and (9) show that the estimates are very similar for the two types of firms, although the small sample size of state-owned firms results in a statistically insignificant estimate.

\footnotetext{
${ }^{35}$ This point has also been made by other studies. See Slemrod (2007) for a discussion.

${ }^{36}$ In this sense, the environment is similar to the the Brazilian one studied by Naritomi (2015).
} 


\subsubsection{Heterogeneous Effects by Size and Fixed Assets}

Given recent studies which find that compliance to tax policy varies by firm size (Bachas and Jensen, 2017; Kleven, Kreiner, and Saez, 2016), we investigate whether the effect of computerization differs for large and small firms in our context. In columns (10) and (11) of Table 4, we observe a larger coefficient for small firms, but the difference between the two coefficients is not statistically significant. ${ }^{37}$

\subsubsection{All Firms}

The main results examine a balanced panel of firms, which has advantages for identification and interpretation because there are no compositional effects from entry and exit of firms. To address the issue of external validity, we re-estimate a specification that is very similar to the baseline equation (3), using all firms and compare those results to those from the balanced panel. This specification includes firm fixed effects, year fixed effects and the interaction of sector average 1998-2000 sales interacted with year fixed effects. ${ }^{38}$ Appendix Table A.6 presents the results. These results suggest that the findings from the balanced sample are qualitatively generalizable to large manufacturing firms as a whole, even if we allow for entry and exit.

\subsection{Other Firm Behavior}

Table 5 examines other measures of firm behavior. Column (1) examines total sales (not just VAT eligible sales), which are reported in a different module of the survey and are generally believed by existing studies to reflect true output. ${ }^{39}$ Columns (2) and (3)

\footnotetext{
${ }^{37}$ We also divide the sample according to the share of fixed assets for the median firm in a sector. We find no difference. These results are available upon request.

${ }^{38}$ Controlling for firm fixed effects cause firms that only exist for one year to drop out of the estimation. These are very few observations. The results are similar if we control for sector-level fixed effects with the full sample of firms. The estimates are also similar if we omit the interaction of year fixed effects with average annual sales. These alternative estimates are available upon request. Appendix Table A.5 presents descriptive statistics for firms in the balanced panel and the full sample.

${ }^{39}$ Many studies have used this variable to measure firm output. The most well-known is perhaps Hsieh and Klenow (2009), which uses this variable to compute firm-level TFP.
} 
examine two proxies of labor input: the number of employees and the total wage bill. The latter is typically problematic to interpret in China because of the high amount of non-wage benefits (e.g., housing). Columns (4)-(5) examine intermediate inputs, first in levels, and then as share of total inputs. Column (6) examines intermediate inputs which are deductible from VAT as a share of total inputs. The results show that the reform reduced sales, employees and deductible input share. The coefficients for the other outcomes are also negative, but imprecisely estimated.

In columns (7) and (8), we examine TFPR, calculated as in Hsieh and Klenow (2009) and as in De Loecker and Warzynski (2012), which accounts for endogenous inputs. We find that the reform increased productivity in both cases. Since productivity is intuitively output normalized by input, this conceptually reflects the fact that the reform reduced inputs more than it reduced output.

In column (9), we examine exports as a share of total sales for each firm as the outcome variable to investigate whether firms shifted towards exports to reduce VAT after the reform. On the one hand, the reform incentivized firms to switch to exports which are eligible for VAT rebates. On the other hand, the earlier results show that the firm is contracting. This may disproportionately reduce exports given the conventional wisdom that there are high fixed costs to exporting (e.g., Das, Roberts, and Tybout, 2007; Roberts and Tybout, 1997). The estimate in column (9) shows that the net effect of the reform on export share is negative and statistically significant at the $10 \%$ level.

\section{Dynamic Effects}

The main results shown in the previous section provide evidence that the reform significantly improved compliance and increased VAT. Consistent with conventional wisdom that the most binding component of the reform was to increase the difficulty of falsifying deduction invoices, we find that the increase in VAT is driven by a decline in deductions. 
We also find that the increase in tax payment was accompanied by a decline in output, input, deductible inputs, export share and an increase in productivity.

This section supplements the main analysis with two complementary inquiries. The first is to ask whether the dynamic effect of the reform on VAT is monotonic or stable over time. This is obviously relevant for policymakers who are interested in longer-run tax revenue gains. The second is to ask whether the effects we observed earlier on sales, inputs and productivity reflect real economic effects or a change in reporting.

It will be beyond the scope of this paper be conclusive about the latter question. But given the importance of the question, it is worthwhile to shed as much light on the issue as the data allow. To motivate the analysis in this section, consider the possibility that our findings on sales, inputs and productivity are driven by a change in what firms report rather than real economic changes. This could occur for two reasons. The first is that firms are motivated to evade VAT. The second is that the new system put in place by the reform causes firms that previously misreported to evade VAT to report all measures of performance more truthfully. The decline in labor inputs and deductible inputs are inconsistent with the first explanation because labor inputs are not deductible and lower deductible inputs increases VAT payment. Finding that the decline in total revenues is larger than the decline on VAT eligible sales is also inconsistent since evasive behavior should induce a larger decline in VAT eligible sales. At the same time, the second explanation is inconsistent with finding that the reform had a negative (2SLS) or no (OLS) effect on VAT eligible sales, and a negative effect on total sales. Firms which previously evaded VAT would have underreported VAT eligible sales, such that an improvement in reporting should increase VAT eligible sales. And as with the first explanation, the decline in labor inputs is difficult to explain since it is unrelated to VAT throughout our study period. Finally, the increase in TFPR is difficult to reconcile with a simple story of evasion.

In other words, the results, taken together are inconsistent with the most obvious 
changes in reporting behavior that could result from the reform. In light of this, we develop a simple model illustrating how the reform can induce real effects, which will have empirically testable predictions for the dynamic effects of the increase in taxation. We will present the conceptual framework and then examine whether the empirical predictions are consistent with our data.

\subsection{Conceptual Framework}

To provide positive evidence that the findings on firm behavior in the previous section are real effects, we develop a simple model. The formal model is presented in Appendix Section F. The intuition is summarized here.

Demand is downward sloping and short-run supply is upward sloping. With no taxes, pre-tax and tax-inclusive prices are similar in period $0, q_{0}=p_{0}$. When the tax, $\tau$, is imposed, the supply shifts upwards by the amount of the tax, since the marginal cost of production has increased by $\tau$. This shift increases the pre-tax equilibrium price to $q_{1}>q_{0}$. Producers receive the pre-tax price minus the tax, $p_{1}=q_{1}-\tau$. The figure shows that the tax-inclusive price will decrease to $p_{1}<p_{0}$.

In the long run, the supply curve becomes more elastic, because we assume that capital (i.e., intermediate inputs) can only be adjusted in the long run. For simplicity, Figure 3 illustrates a perfectly elastic long-run supply curve. Since $q_{0}=p_{0}$ is optimal, we simply rotate the supply curve around the initial point where supply and demand intersect. As with the short-run, the long-run response to the increase in taxes can be illustrated by shifting the supply curve up by the amount of the tax. The long-run pre-tax price will be $q_{2}>q_{1}>q_{0}$, while the long-run tax-inclusive price will be $p_{2}=p_{0}$. Figure 3 illustrates the key intuition.

The simple model also predicts that labor input will decline over time. The intuition for this result comes from the observation that the short-run elasticity of labor is smaller than the long-run elasticity of labor (because capital can also be adjusted in the long 
run) holding pre-tax prices fixed. This effect implies that labor should react even more in the long run to the tax change than in the short run. In our setting, there is also an offsetting effect, since the increase in pre-tax prices calls for larger inputs, all things being equal. If demand is elastic, prices react little to changes in output, so that the first effect dominates. It follows with additional algebra that other inputs also decline over time.

Several empirically testable implications emerge from the model. First, tax revenues will increase from period zero to period one, and then decline in period 2 to a level between that of periods zero and one, such that $0=\operatorname{taxes}_{0}<\operatorname{taxes}_{2}<\operatorname{taxes}_{1} \cdot{ }^{40}$ Second, the pre-tax price, which is algebraically equivalent to TFPR as formulated in Hsieh and Klenow (2009), increases every period, $q_{2}>q_{1}>q_{0}$. Third, if the elasticity of demand, $\sigma$, is greater than 1 , sales decline each period, $q_{2} y_{2}<q_{1} y_{1}<q_{0} y_{0}$. Fourth, labor and intermediate inputs decline each period, $l_{0}>l_{1}>l_{2}$ and $k_{0} \geq k_{1}>k_{2}$.

The baseline model assumes a Cobb-Douglas production function with two factors, labor and intermediate inputs, and perfect competition. We provide several extensions to show that all of the main insights carry through with imperfect competition, endogenous input prices, or with three factors of production (labor, capital, and deductible inputs). ${ }^{41}$ See Appendix Section F.

\subsection{Results}

The first prediction of the simple model is that tax revenues should increase after the reform, but the long-run level - though still positive - will be slightly lower than the short-run level. Recall that Figure 2 indicates that this is the case.

We can also examine this by re-estimating an OLS equation similar to the baseline,

\footnotetext{
${ }^{40}$ Taxes $_{t}=\tau q_{t} y_{t}$

${ }^{41}$ Note that because our empirical strategy relies on cross-sector as well as time variation, the results, taken literally, will also reflect the ability of factors to reallocate across sectors. For simplicity, our baseline model does not take this additional mechanism into account. The extension is straightforward and available upon request. All of the insights carry through.
} 
except that we divide the seven-year post-reform period into three sub-periods: 20012002, 2003-2005, and 2006-2007. ${ }^{42}$ Table 6 column (1) examines gross VAT. Column (2) examines deductions. These results are consistent with the average effects of the reform shown earlier. The estimates for gross VAT are negative, but statistically indistinguishable from zero. The estimates for deductions are negative, statistically significant starting in 2003 and larger in magnitude than the decline in sales.

Column (3) shows that the reform increases VAT payment in all three post-reform periods. However, the increase is largest in levels during 2003-2005 and declines in the third period. The non-monotonic pattern over time is consistent with the predictions of our model. The p-values at the bottom of the table show that the change from period one to period two is statistically significant at the $1 \%$ level. The decline from period two to period three is almost significant at the $15 \%$ level. The coefficients from periods one and three are statistically similar. The evidence suggests that the gains in VAT from the reform decline slightly in the long run, but remain positive.

Column (4) examines VAT as a share of sales. The temporal patterns are consistent with those in column (3).

Table 7 columns (1) and (6) show that the increase in taxes is accompanied by a monotonic decline in sales and deductible input share. The other coefficients are also declining monotonically over time, but are statistically insignificant. Columns (7) and (8) show that TFPR increases over time.

All of the results are consistent with the theory which predicts real effects.

In column (9), we examine export share and see that the negative effect of the reform is monotonic over time. It parallels the reduction in output.

As with our earlier results, we show that the estimates exhibit similar patterns when we instrument for Chinese non-deductible shares with U.S. non-deductible shares. The

\footnotetext{
${ }^{42}$ Recall that for the earlier estimates of the average effect of the reform, we defined the post-reform period as 2002 and afterwards because the reform was only partly phased in during 2001. Here, in the dynamic estimation, we allow both 2001 and 2002 to be the first treatment period so that we can observe the effects during the entire period of program rollout.
} 
results are presented in Appendix Table A.7. We do not show the results instrumenting with Mexican and South Korean non-deductible shares because the first-stage F-statistics for these alternative instruments are very small in the dynamic estimate. We also report the robustness of dynamic effects subject to the same large set of controls we examined earlier in Appendix Table A.8.

\section{Conclusion}

This paper documents that a large-scale nation-wide, but relatively straight-forward reform which computerized and digitally encrypted VAT invoices significantly resulted in huge gains for government revenues. We also find that the reform reduced firm output and provide evidence that firms could be contracting production in response to the increase in effective tax rate. At the same time, we find that productivity increases. Thus, from the perspective of the government or economy as a whole, the contraction in firm size is not necessarily bad. The dynamic effects on tax revenues are nuanced. The gains in revenues are smaller in the long run than the short run, but important for policy makers, they remain positive. These results are consistent with firms being able to adjust production more in the longer run than the short run.

It is important to keep in mind that the magnitudes of our estimates are specific to the context of our study. However, the insights that a simple technology can have a large effect on state capacity, or that firms may change their economic behavior in the longer run as a response to increased taxes, are generalizable. 


\section{References}

Bachas, P., And A. Jensen (2017): "Size-Dependent Tax Enforcement and Compliance: Global Evidence," Working paper, Harvard Kennedy School.

BAI, J., AND J. LiU (2017): "The Impact of Local Trade Barriers on Export Activities, Firm Performance, and Resource Misallocation," Working paper, Harvard Kennedy School.

Banerjee, A. V., E. Duflo, and R. Glennerster (2008): "Putting a band-aid on a corpse: Incentives for nurses in the Indian public health care system," Journal of the European Economic Association, 6(2-3), 487-500.

Barnwal, P. (2016): "Curbing Leakage in Public Programs with Direct Benefit Transfers: Evidence from India's Fuel subsidies and Black Markets," Working paper, Michigan State University.

Benzarti, Y., D. Carloni, J. Haruu, and T. Kosonen (2017): "What goes up may not come down: Asymmetric Incidence of Value-Added Taxes," Working paper, UCLA.

Besley, T., And T. Persson (2009): "The Origins of State Capacity: Property Rights, Taxation, and Politics," American Economic Review, 99(4), 1218-1244.

$1-34$

(2010): "State Capacity, Conflict, and Development," Econometrica, 78(1),

CAI, H., AND Q. LiU (2009): "Competition and corporate tax avoidance: Evidence from Chinese industrial firms," The Economic Journal, 119(537), 764-795.

Cai, J., And A. Harrison (2011): "The Value-Added Tax Reform Puzzle," Working Paper 17532, National Bureau of Economic Research.

Chandra, P., and C. Long (2013): "VAT Rebates and Export Performance in China: Firm-Level Evidence," Journal of Public Economics, 103, 13-22.

Chen, S. X. (2017): "The effect of a fiscal squeeze on tax enforcement: Evidence from a natural experiment in China," Journal of Public Economics, 147, 62-76.

Chen, Z., Z. Liu, J. C. S. Serrato, and D. Y. Xu (2017): "Notching R\&D Investment with Corporate Income Tax Cuts in China," Working paper, Duke University.

Chernozhukov, V., And C. Hansen (2008): "The reduced form: A simple approach to inference with weak instruments," Economics Letters, 100(1), 68-71.

China Tax Audit Yearbook Committee (2002): China's Tax Audit Yearbook. China Taxation Publishing House.

(2003): China's Tax Audit Yearbook. China Taxation Publishing House. 
— (2004): China's Tax Audit Yearbook. China Taxation Publishing House. (2007): China's Tax Audit Yearbook. China Taxation Publishing House.

China's National Bureau of Statistics (1999): Input-Output Tables of China in 1997 (124 Industries). China Statistics Press.

Das, S., M. J. Roberts, and J. R. Tybout (2007): "Market entry costs, producer heterogeneity, and export dynamics," Econometrica, 75(3), 837-873.

De Loecker, J., And F. Warzynski (2012): "Markups and firm-level export status," The American Economic Review, 102(6), 2437-2471.

Dietzenbacher, E., B. Los, R. Stehrer, M. Timmer, and G. De Vries (2013): "The construction of world input-output tables in the WIOD project," Economic Systems Research, 25(1), 71-98.

Duflo, E., R. Hanna, and S. P. Ryan (2012): "Incentives Work: Getting Teachers to Come to School," American Economic Review, 102(4), 1241-1278.

Fan, H., X. GaO, Y. A. Li, and T. A. Luong (2018): "Trade liberalization and markups: Micro evidence from China," Journal of Comparative Economics, 46(1), $103-130$.

Fan, H., Y. A. Li, And S. R. Yeaple (2015): "Trade liberalization, quality, and export prices," Review of Economics and Statistics, 97(5), 1033-1051.

Gadenne, L., T. K. Nandi, and R. Rathelot (2019): "Taxation and Supplier Networks: Evidence from India," CAGE Online Working Paper Series 428, Competitive Advantage in the Global Economy (CAGE).

Garred, J. (2016): "The Persistence of Trade Policy in China After WTO Accession," Working paper.

Gordon, R. H., And W. Li (2009): "Tax Structures in Developing Countries: Many Puzzles and a Possible Explanation," Journal of Public Economics, 93(7-8), 855-866.

Harju, J., T. Matikka, and T. Rauhanen (2015): "The Effect of VAT on the Behavior of Small Businesses: Evidence and Implications," Working paper.

Hsieh, C.-T., And P. J. Klenow (2009): "Misallocation and Manufacturing TFP in China and India," Quarterly Journal of Economics, 124(4), 1403 -1448.

Hsien, C.-T., And Z. Song (2017): "Grasp the Large, Let Go of the Small: The Transformation of the State Sector in China," Brookings Papers on Economic Activity, Forthcoming.

Internal Revenue Service (2001): "Data Book 2000," Publication 55B, Washington $D C$. 
JIN, R. (2002): "Unify the Mind and Get Prepared: Push Forward the Information Technology in Taxation," Direct Speech at the National Conference of the Information Technology Implementation in the Tax System.

Keen, M., And B. Lockwood (2010): "The Value-Added Tax: Its Causes and Consequences," Journal of Development Economics, 92(2), 138-151.

Kleven, H. J., C. T. Kreiner, and E. Saez (2016): "Why Can Modern Governments Tax So Much? An Agency Model of Firms as Fiscal Intermediaries," Economica, $83(330), 219-246$.

Kleven, H. J., And M. Waseem (2013): "Using Notches to Uncover Optimization Frictions and Structural Elasticities: Theory and Evidence from Pakistan," The Quarterly Journal of Economics, 128(2), 669-723.

Kopczuk, W., And J. Slemrod (2006): "Putting Firms into Optimal Tax Theory," American Economic Review, 96(2), 130-134.

LIU, Q., AND Y. LU (2015): "Firm Investment and Exporting: Evidence from China's Value-Added Tax Reform," Journal of International Economics, 97(2), 392-403.

LiU, Y., And J. MaO (2019): "How Do Tax Incentives Affect Investment and Productivity? Firm-Level Evidence from China," American Economic Journal: Economic Policy, 11(3), 261-91.

Lu, R. (1997): "See the Situation and Unify the Mind: Raise the Tax Audit Quality to a Higher Level," National Tax Audit Conference.

Ministry OF Finance (1993): "Detailed Rule for the Implementation of the Provisional Regulations of the People's Republic of China on Value-added Tax," .

Mittal, S., And A. Mahajan (2017): "VAT in Emerging Economies: Does Third Party Verification Matter?," Working paper, UC Berkeley.

Muralidharan, K., P. Niehaus, And S. Sukhtankar (2016): "Building State Capacity: Evidence from Biometric Smartcards in India," The American Economic Review, 106(10), 2895-2929.

Naritomi, J. (2015): "Consumers as Tax Auditors," Working paper, London School of Economics.

National Bureau of Statistics (2003): "China Statistical Yearbook," .

OECD (2016): "Revenue Statistics 2016," .

Piketty, T., E. Saez, and S. Stantcheva (2014): "Optimal Taxation of Top Labor Incomes: A Tale of Three Elasticities," American Economic Journal: Economic Policy, 6(1), 230-71. 
Pomeranz, D. (2015): "No taxation without information: Deterrence and selfenforcement in the value added tax," The American Economic Review, 105(8), 2539 2569.

Roberts, M. J., and J. R. Tybout (1997): "The Decision to Export in Colombia: An Empirical Model of Entry with Sunk Costs," The American Economic Review, $87(4), 545-564$.

Saez, E., J. Slemrod, and S. Giertz (2012): "The Elasticity of Taxable Income with Respect to Marginal Tax Rate: A Critical Review," Journal of Economic Literature, $50(1), 3-50$.

Samuelson, P. A. (1949): "The Le Chatelier principle in linear programming.," .

Slemrod, J. (2007): "Cheating Ourselves: The Economics of Tax Evasion," Journal of Economic Perspectives, 21(1), 25-48.

State Administration of Taxation (2000): "Notice on Implementing the Valueadded Tax Control Devices," Guo Shui Fa [2000] no.191.

State Council (1993): "Provisional Regulations of the People's Republic of China on Value-added Tax," .

Timmer, M., B. Los, R. Stehrer, And G. De VRies (2016): "An anatomy of the global trade slowdown based on the WIOD 2016 release," Discussion paper, Groningen Growth and Development Centre, University of Groningen.

U.S. Bureau of Economic Analysis (2007): "Input-Output Accounts Data: Detailed Use Tables Before Redefinitions in Producer Value in 2007 (405 Industries),"

(2017): "Input-Output Accounts Data: The Use of Commodities by Industries in 1997-2017 (71 Industries)," .

WAseem, M. (2019): "Information, Asymmetric Incentives, Or Withholding? Understanding the Self-Enforcement of Value-Added Tax," CESinfo Working Paper No. 7736. 
Table 1: Correlates of Non-deductible Share and Pre-Reform Firm Characteristics

\begin{tabular}{lc}
\hline \hline Pre-Reform Means & $\begin{array}{c}\text { Sector-Level Non- } \\
\text { Deductible Share }\end{array}$ \\
\hline VAT & $.1924 * * *$ \\
VAT / Sales & $.443 * * *$ \\
VAT Gross & -.0764 \\
VAT Deductions & $-.159 * *$ \\
TFPR OLS & $.3933 * * *$ \\
TFPR DLW & $.2412^{* * *}$ \\
Sales & $-.1443 * *$ \\
Empl & .0071 \\
Wage Bill & .0325 \\
Intermediate Inputs & $-.1774 * *$ \\
Intermediate Input Share & $-.3046 * * *$ \\
Total Deductible Inputs & $-.1082 *$ \\
Export Share & -.0778 \\
\hline Notes $:$ This table presents the standardized bivariate correlation \\
coefficients between the non-deductible share and key variables \\
measured in 1998-2000. *** p<0.01, $* *$ p $<0.05, *$ p $<0.1$
\end{tabular}


Table 2: The Effect of Computerization on VAT

\begin{tabular}{|c|c|c|c|c|}
\hline & \multicolumn{4}{|c|}{ Dependent Variables } \\
\hline & $(1)$ & $(2)$ & (3) & (4) \\
\hline & & VAT & & \\
\hline & VAT Gross & Deductions & VAT & VAT/Sales \\
\hline \multirow[t]{2}{*}{ Dep Var Mean } & 7,758 & 6,194 & 2,043 & 0.0418 \\
\hline & \multicolumn{4}{|c|}{ A. OLS } \\
\hline \multirow[t]{2}{*}{ Non-deductible share x Post-2002 } & $-3,881$ & $-5,312 * *$ & $1,187 * *$ & $0.00976 *$ \\
\hline & $(2,544)$ & $(2,234)$ & $(490.7)$ & $(0.00562)$ \\
\hline Observations & 180,148 & 180,148 & 180,148 & 180,148 \\
\hline \multirow[t]{2}{*}{ R-squared } & 0.626 & 0.500 & 0.692 & 0.560 \\
\hline & \multicolumn{4}{|c|}{ B. 2SLS } \\
\hline Non-deductible share x Post-2002 & $\begin{array}{c}-14,637 * * * \\
(5,625)\end{array}$ & $\begin{array}{c}-16,526 * * * \\
(4,973)\end{array}$ & $\begin{array}{c}1,336 \\
(1,234)\end{array}$ & $\begin{array}{l}0.0347 * * \\
(0.0138)\end{array}$ \\
\hline Observations & 180,148 & 180,148 & 180,148 & 180,148 \\
\hline \multirow[t]{2}{*}{ Kleibergen-Paap F-statistic } & 26.65 & 26.65 & 26.65 & 26.65 \\
\hline & \multicolumn{4}{|c|}{ C. Reduced Form } \\
\hline U.S. Non-deductible share x Post-2002 & $\begin{array}{c}-3,468 * * * \\
(1,309)\end{array}$ & $\begin{array}{c}-3,915^{* * *} \\
(1,131)\end{array}$ & $\begin{array}{c}316.5 \\
(288.8)\end{array}$ & $\begin{array}{c}0.00823^{* * *} \\
(0.00301)\end{array}$ \\
\hline Observations & 180,148 & 180,148 & 180,148 & 180,148 \\
\hline R-squared & 0.626 & 0.500 & 0.692 & 0.560 \\
\hline
\end{tabular}




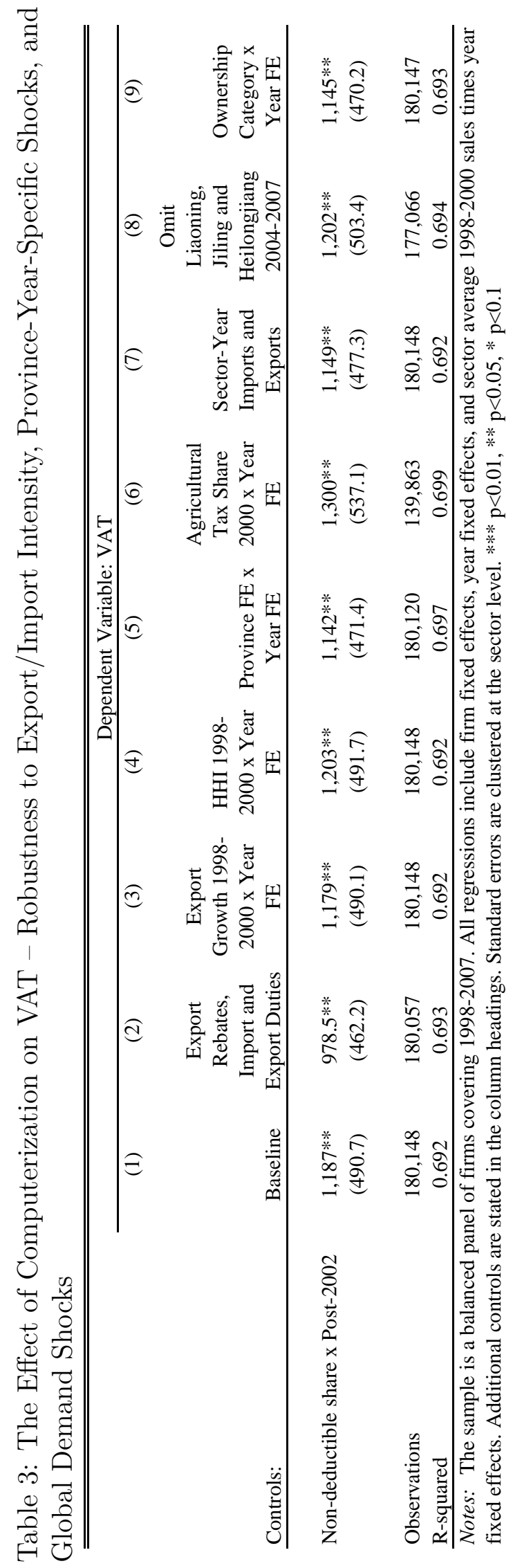




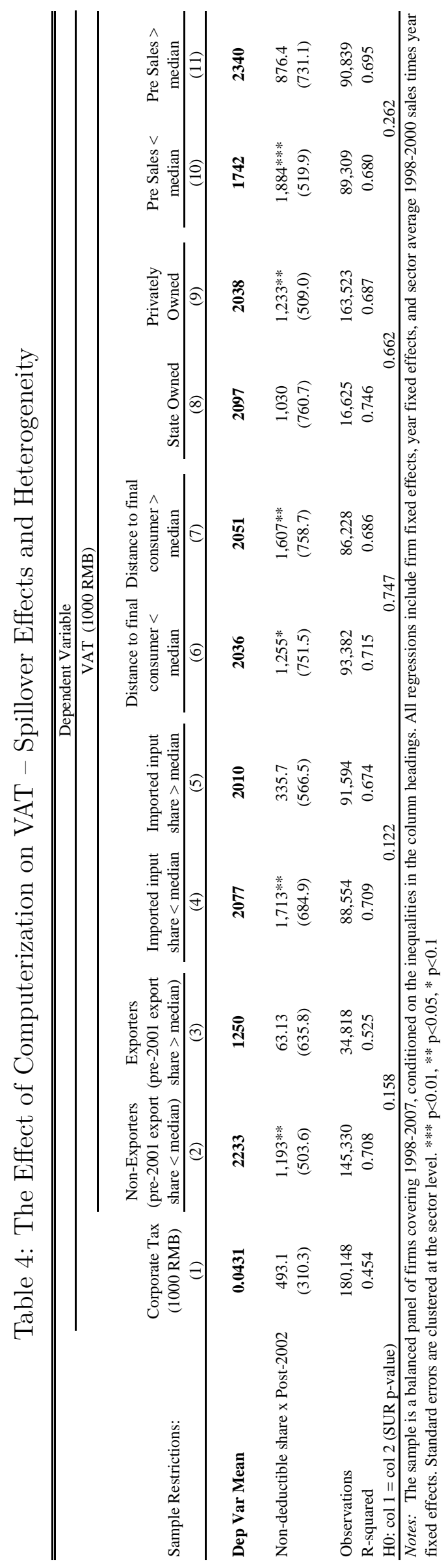




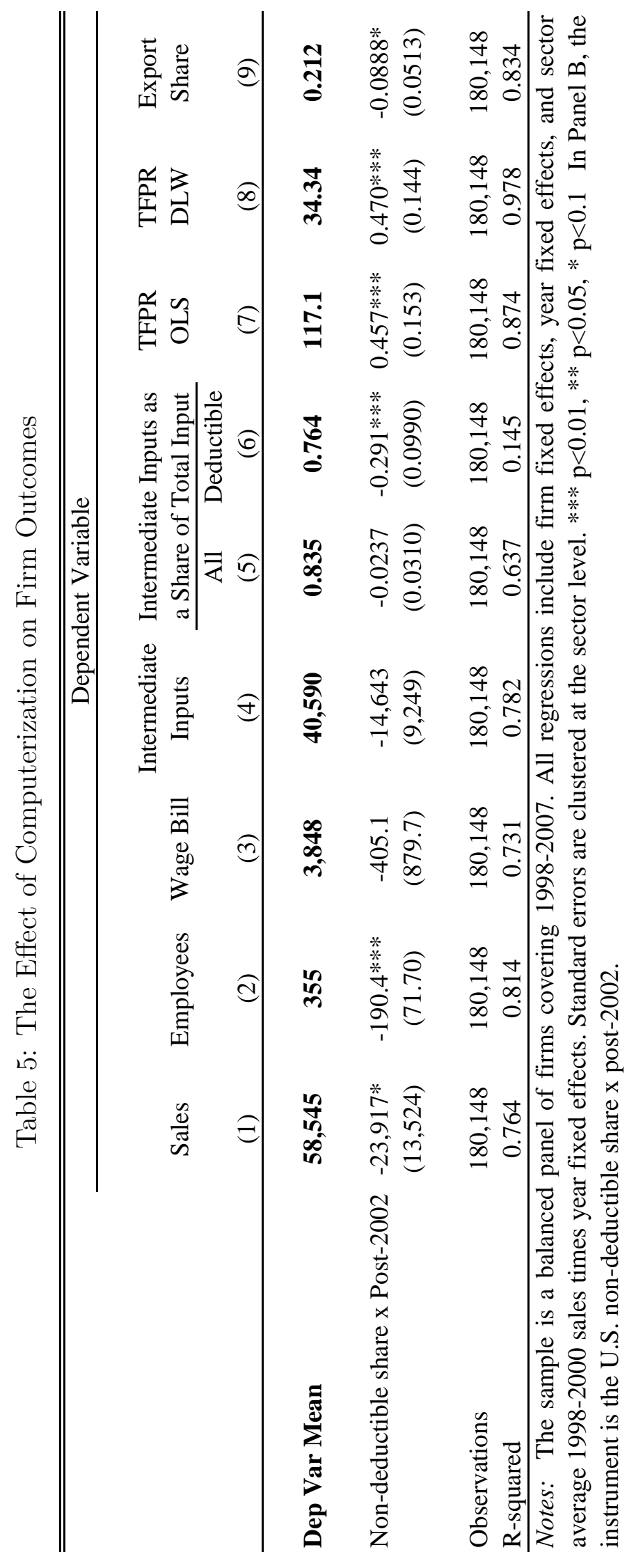


Table 6: The Effect of Computerization on VAT - Dynamic Effects

\begin{tabular}{|c|c|c|c|c|}
\hline & \multicolumn{4}{|c|}{ Dependent Variable } \\
\hline & $(1)$ & $(2)$ & $(3)$ & $(4)$ \\
\hline & VAT Gross & VAT Deductions & VAT & VAT/Sales \\
\hline Non-deductible share $\mathrm{x}$ 2001-2002 ( $\beta 1)$ & $\begin{array}{l}-455.5 \\
(930.2)\end{array}$ & $\begin{array}{l}-1,129 \\
(820.2)\end{array}$ & $\begin{array}{c}618.8 * \\
(364.2)\end{array}$ & $\begin{array}{c}0.00364 \\
(0.00351)\end{array}$ \\
\hline Non-deductible share $\mathrm{x}$ 2003-2005 ( $\beta 2)$ & $\begin{array}{l}-3,021 \\
(2,029)\end{array}$ & $\begin{array}{c}-3,615^{* *} \\
(1,781)\end{array}$ & $\begin{array}{c}1,667 * * * \\
(599.9)\end{array}$ & $\begin{array}{l}0.0125^{* *} \\
(0.00618)\end{array}$ \\
\hline Non-deductible share $\mathrm{x}$ 2006-2007 ( $\beta 3$ ) & $\begin{array}{c}-5,584 \\
(4,049)\end{array}$ & $\begin{array}{c}-8,901^{* *} \\
(3,512)\end{array}$ & $\begin{array}{l}1,100 * \\
(666.1)\end{array}$ & $\begin{array}{c}0.00943 \\
(0.00733)\end{array}$ \\
\hline Observations & 180,148 & 180,148 & 180,148 & 180,148 \\
\hline R-squared & 0.626 & 0.500 & 0.692 & 0.560 \\
\hline H0: $\beta 1=\beta 2$ (p-value) & 0.100 & 0.0800 & 0.00400 & 0.0660 \\
\hline H0: $\beta 2=\beta 3$ (p-value $)$ & 0.323 & 0.0230 & 0.159 & 0.443 \\
\hline H0: $\beta 1=\beta 3$ (p-value) & 0.170 & 0.0210 & 0.359 & 0.350 \\
\hline
\end{tabular}




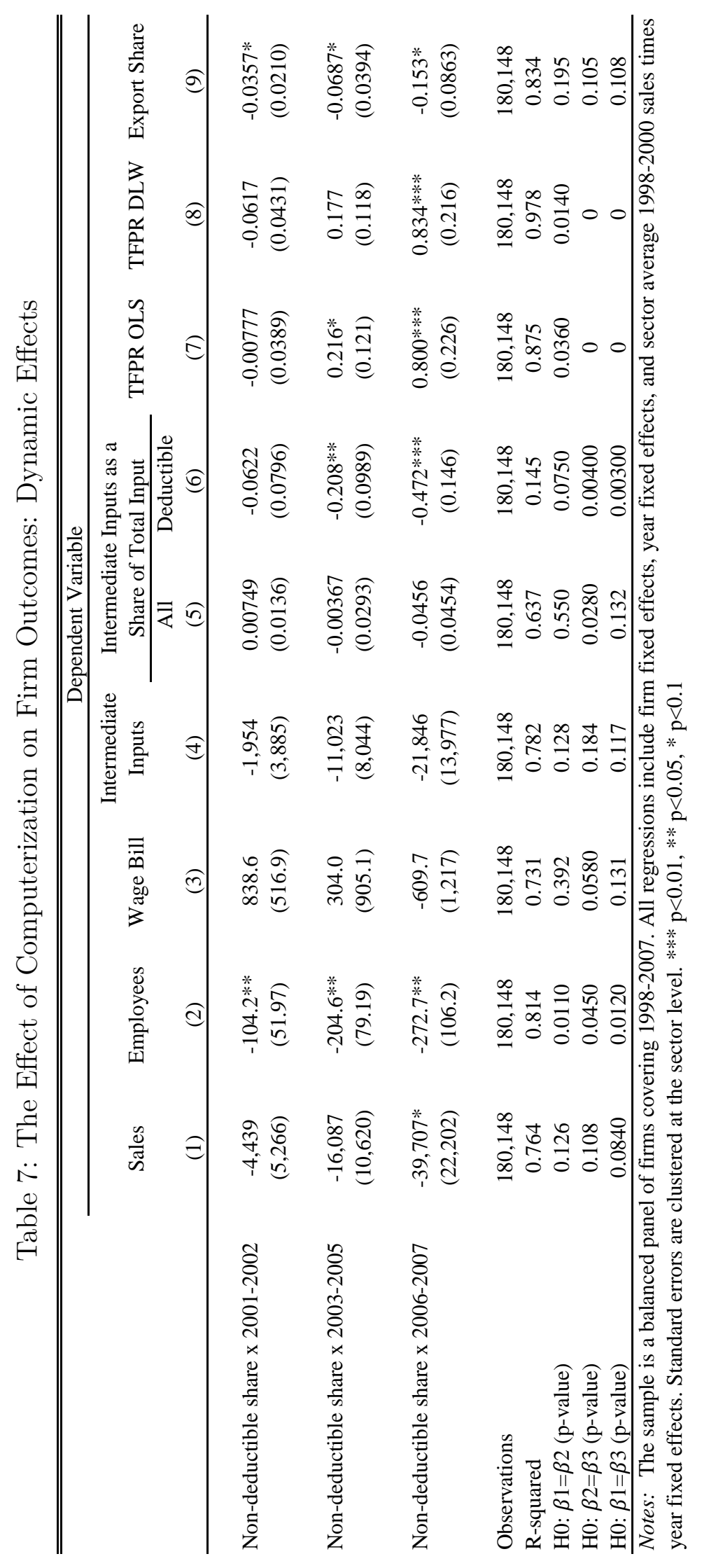


Figure 1: VAT Over Time for Firms with Non-deductible Shares Above and Below the Sample Median

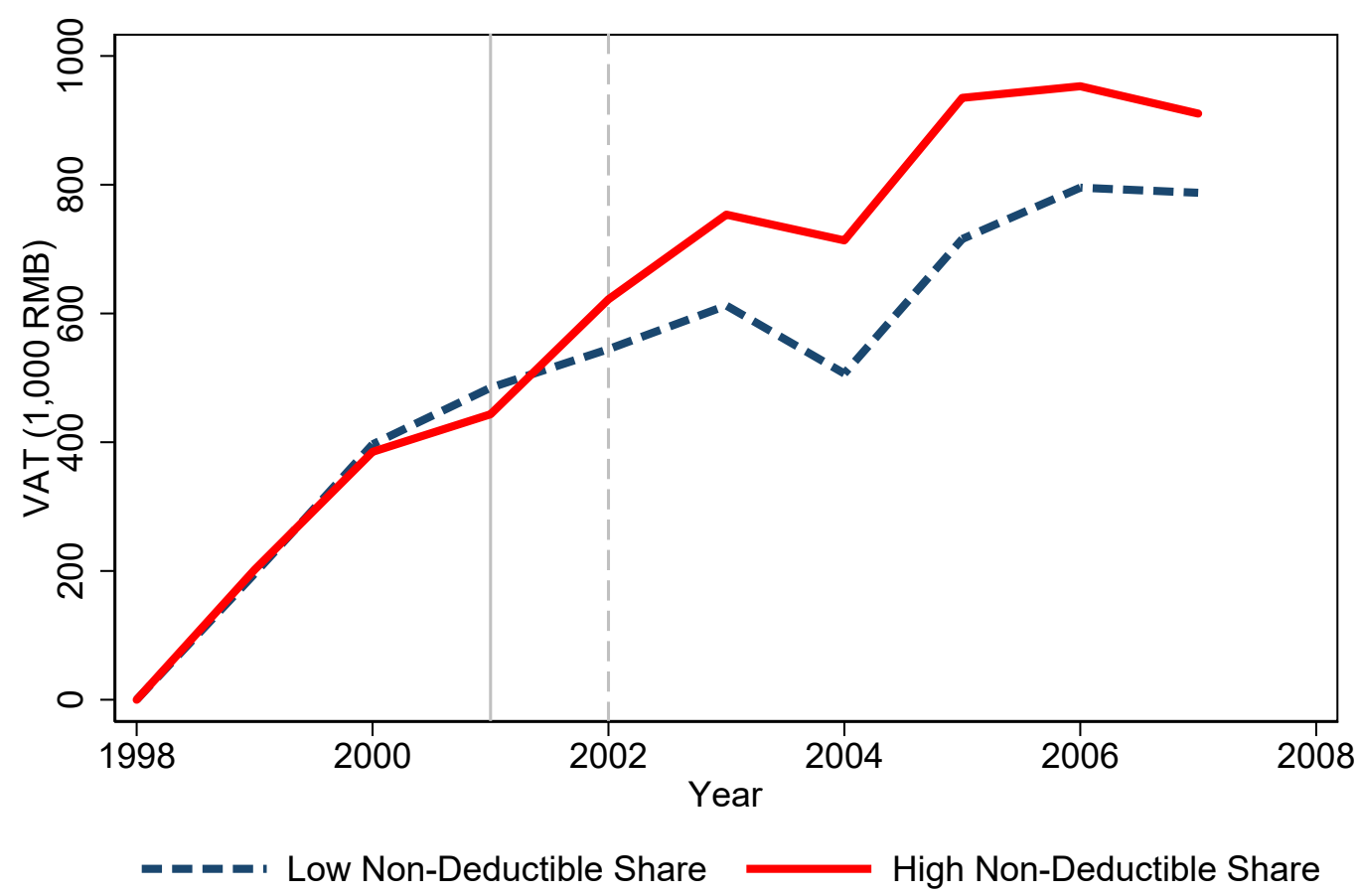

Notes: For each of the two groups of firms, the 1998 mean is subtracted from the yearly value. 
Figure 2: The Yearly Effect of Computerization on VAT

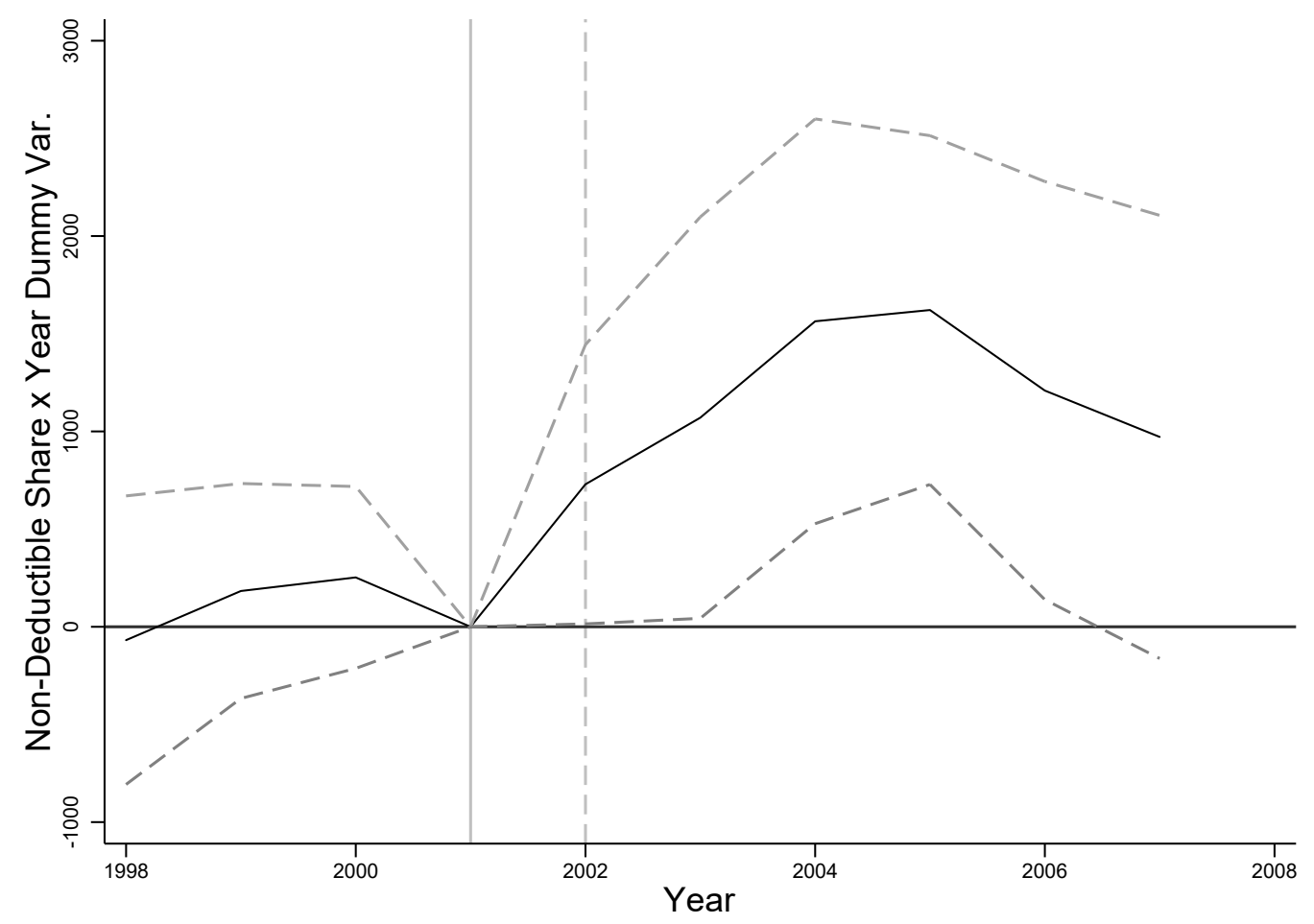

Notes: This figure plots the interaction coefficients of non-deductible share and year dummy variables (controlling for year and firm fixed effects) and their 95\% confidence intervals. The sample is a balanced panel of firms, 1998-2007. The reference year is 2001. The coefficients and their standard errors are shown in Appendix Table A.9. 
Figure 3: Illustration of Short- and Long-run Responses to VAT

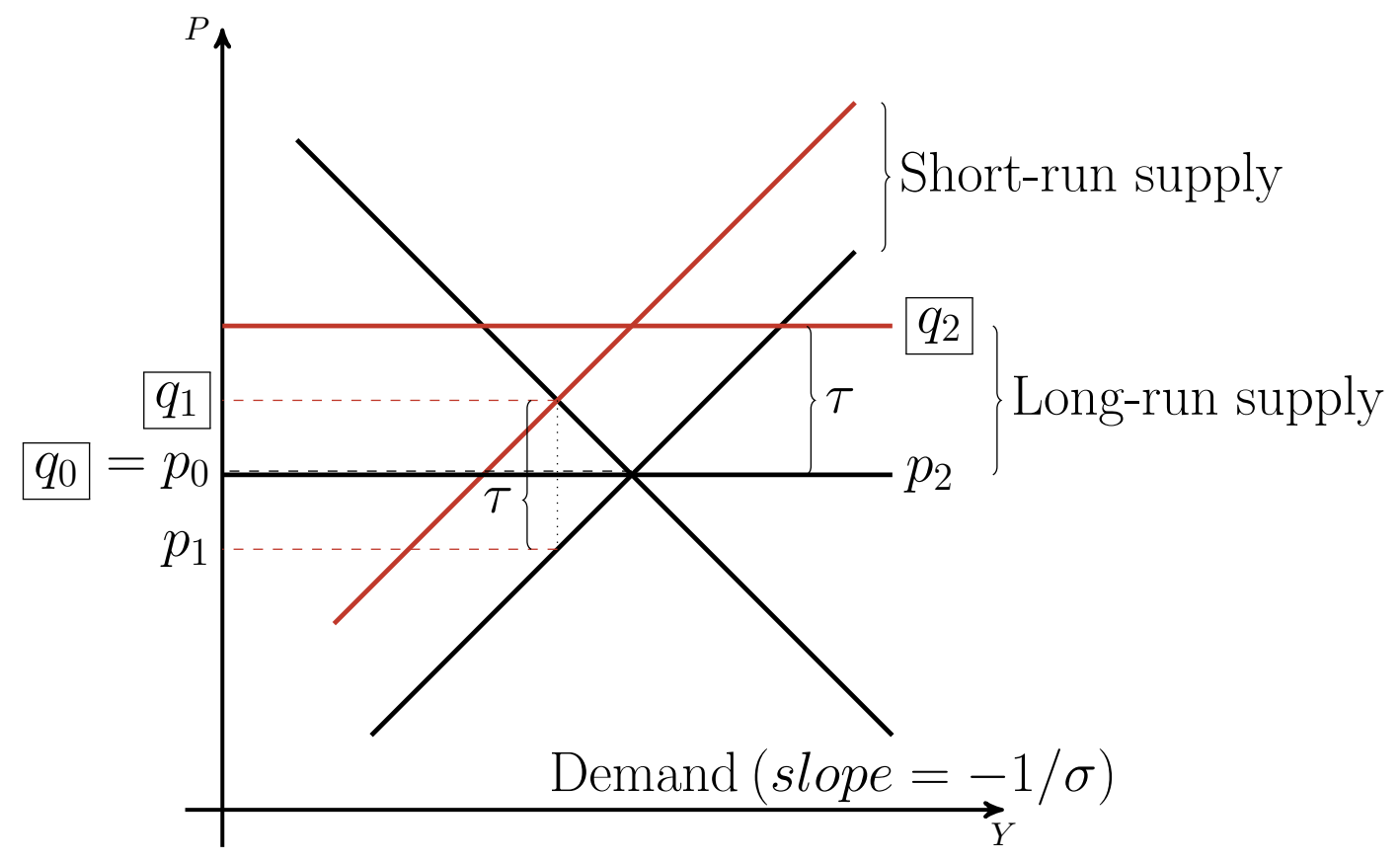




\section{APPENDIX}

\section{A Other Enforcement Mechanisms (Audits)}

The Chinese SAT is a large bureaucracy. This fact can be observed in data reported by the China Tax Audit Yearbook Committee (2007). The dashed blue line in Appendix Figure A.1 presents the number of tax officials per province over time. On average, there are 12,688. The spike in 2002 reflects the additional personnel hired to implement the reform that we study. Note that with the exception of 2002, the number of tax officials per province is similar over time during the years that we study, 1998-2007. However, it begins to decline in later years. This is consistent with the fact that other compliance mechanisms (e.g., inspections, audits) did not experience systematic changes right after computerization, but a broader over-haul began after 2010 .

The dashed black line in Appendix Figure A.1 shows the rate of audits per province over time from 2000-2007, the only years for which such data are available. ${ }^{43}$ On average, the SAT conducted 22, 999 audits per province per year, and the value declined steadily through this time period. The decline is consistent with anecdotal evidence that the computerization was meant to reduce the reliance on manual audits.

The China Tax Audit Yearbook Committee (2007) also reports the number of audits that indicate problematic behavior and the number of cases that are fined. The solid red line in Appendix Figure A.1 plots the rate of problematic audits over the years when such data are available. On average, the percentage of problematic cases before computerization is $7.7 \%$ of all filings (China Tax Audit Yearbook Committee, 2007). However, very few of these are prosecuted and the fines are moderate. For example, in 1997, the penalty as a share of SAT's estimate of unpaid taxes was below 5\%, which was lower than the interest rate (China Tax Audit Yearbook Committee, 2002); in 2002,

\footnotetext{
${ }^{43}$ The personnel data are reported by the Tax Yearbooks of China; the audit rate data are reported by the Tax Audit Yearbooks of China.
} 
among the 112,984 tax-fraud cases investigated by tax officials, only 2,658 cases were prosecuted (China Tax Audit Yearbook Committee, 2003). This is reportedly due to the difficulty of providing conclusive evidence and the inability of the tax authority to accurately estimate the amount of evasion without the true transaction amounts or linked transactions.

To the best of our knowledge, there are no disaggregated data on audits that are available to researchers. In interviews conducted by the authors, regional and local tax officials state that they target firms and sectors with high levels of deductibles as a share of sales to inspect and audit. This targeting rule of thumb did not change after the computerization of invoices.

\section{B VAT Deductibles}

The regulation that governs VAT remittance rules during the study period is the Provisional Regulations of the People's Republic of China on Value-Added Tax (State Council Order 134, published in December 1993). The rules were effective between Jan 1, 1994, and Jan 1, 2009, when these Regulations were amended for the first time. The Regulations specifies the deductible items for VAT, which are not exactly the same as in other countries. The general principle is that any purchases that come with VAT special invoices, regardless of whether they originate from a domestic or international seller, can be deducted from the VAT duty. Full deductions are allowed for manufactured inputs, repair inputs, retail inputs, and wholesale inputs. Partial deductions are allowed for some "necessity goods" (including agricultural products, oils, gas, book, fertilizers, salt, and etc.) at a rate of $13 \%$, for old and waste materials at a rate of $10 \%$, and for transportation costs at a rate of $7 \%$. No deductions are allowed for labor costs, fixed asset purchases, capital depreciation, abnormal losses, rent, fringe benefits, interests from bank loans, and overhead/operating expenses. Three Northeastern provinces, namely 
Liaoning, Jilin, and Heilongjiang, experimented with variants of VAT reforms in eight sectors in 2004 that allowed for deductions of fixed asset purchases. However, this did not affect other regions until 2009.

\section{Data}

We follow the standard procedure for cleaning the Manufacturing Censuses, as first used in Cai and Liu (2009). We drop observations for which any reported sub-component of assets is greater than total assets, as well as observations for which the start month does not fall between 1 and 12. We also drop observations for which the founding year of the firm is greater than the year of the survey.

We remove the influence of extreme outliers, which are likely to represent coding errors in these self-reported data. We drop the top and bottom $1 \%$ of observations for the variables VAT and sales.

We construct measures of non-deductible share for several countries using the World Input-Output Tables (Dietzenbacher, Los, Stehrer, Timmer, and De Vries, 2013; Timmer, Los, Stehrer, and de Vries, 2016). We use input-output tables from the year 2000 to construct these alternative country non-deductible shares, as that is the first available year for which the tables are reported with 56 sectors. For years prior to 2000, the

World Input-Output Tables are reported at an aggregation of 35 sectors. We create a correspondence between the 56 input sectors and whether each sector would legally be considered a non-deductible input type under Chinese tax law in the year 2000. Then, we compute the sector-and-country-specific share of each industry's inputs that are not deductible. 


\section{Back-of-the-Envelope Calculations}

Contribution to the Decline in Total VAT deductions We compute the average treatment effect for VAT deductions by multiplying the estimated coefficient from Table 2 Panel A Column (2), -5,312; the mean value of non-deductible share in the sample, 0.4042; five, the number of years in the post period; and 1,000, since the variable is reported in thousands of $\mathrm{RMB}:-5,312 \times 0.4042 \times 5 \times 1000=-10,735,552 \mathrm{RMB}$. To compute VAT deductions in the absence of treatment, we predict VAT deduction as the linear combination of the third and fourth terms of equation (3). Among firms that have mean non-deductible share in the post period, the average of this net predicted value is 9, 793.42. To obtain the cumulative value for the five years of post-treatment period in terms of RMB, we calculate $9,793.42 \times 5 \times 1,000=48,967,105$ RMB. We divide the treatment effect by this value and find that the treatment effect accounts for $21.92 \%$ of the decline in total VAT deductions during 2003-2007: $-10,735,552 / 48,967,105=-0.2192$.

Contribution to VAT Revenues We compute the average treatment effect for VAT payments using the same steps as for VAT deductibles. We multiply the estimated coefficient from Table 2 Panel A Column (3), 1, 187; the mean value of non-deductible share in the sample, 0.4042; five, the number of years in the post period; and 1,000, since the variable is reported in thousands of RMB: $1,187 \times 0.4042 \times 5 \times 1000=2,398,927$ RMB. To compute VAT payments in the absence of the treatment effect, we predict VAT payment as the linear combination of the third and fourth terms of equation (3). Among firms that have mean NDS, the average predicted value is 1769.6 in the post period. To obtain the cumulative RMB value for the five years of the post period, we calculate $1769.604 \times 5 \times 1,000=8,848,020$ RMB. We divide the treatment effect by this value to obtain the percent contribution of the treatment on total VAT payments, 2003-2007: $2,398,927 / 8,848,020=0.2711$. Because VAT revenues are $47.6 \%$ of total government revenues in 2002 , the treatment contributes to $27.11 \times 47.6=12.9 \%$ of government 
revenues.

\section{E 2SLS Estimate}

To calculate the United States non-deductible shares, we use the United States InputOutput Accounts Data from the U.S. Bureau of Economic Analysis (2017). These tables report the share of inputs by sector required in order to deliver one dollar of output. The sectors are coded with the North American Industry Classification System (NAICS) at three levels of disaggregation: a 13-sector coding, a 71-sector coding and a 405-sector coding. The 13- and 71-sector tables are available for each year from 1997 to 2017. The finest level of disaggregation, with 405 sectors, is only available for 2007 and 2012. In selecting which U.S. I-O table to use, we balance two objectives.

First, we want the most disaggregated data in order to lose as little information as

possible in the concordance process. To assess the importance of disaggregation, we tabulated how much information would be lost in moving from 405 to 71 sectors. When we hand-match sectors in the 71-sector NAICS codes to the CIC, each NAICS code is matched with an average of 13.7 Chinese sectors. When we match the 405 -sector NAICS codes with the CIC, each NAICS code is matched with an average of 1.9 Chinese sectors. As a result, significantly more information is lost when harmonizing the 71-sector NAICS codes to CIC codes.

Second, we would like to use pre-computerization data to avoid the inclusion of endogenous treatment effects in our measurement of U.S. non-deductible share. Specifically, the Chinese computerization in 2001-2002 may have precipitated changes in the Chinese economy, and in turn, those changes may have altered the composition of U.S. firm inputs in the years after 2001, perhaps through international trade linkages.

However, there are no pre-computerization U.S. Tables that report at the 405 -sector level. Thus, we choose to use the 2007 Detailed Input U.S. Tables (U.S. Bureau of 
Economic Analysis, 2007).

The 2007 Detailed Input U.S. Table reports the share of inputs required for one unit of production in industry $s$ from all other industries. Hence, the elements of the table report Input fraction $r$, for $r, s \in S$, where $S$ represents the universe of all sectors. For

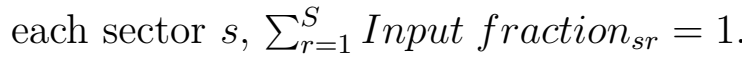

To construct our measure of U.S. NDS, we map each sector in the input-output tables into two groups, deductible or non-deductible, according to the rules of the Chinese VAT deductions. In practice, we consider inputs from agricultural, mining, and manufacturing industries to be materials, and thus deductible under Chinese VAT rules. We treat inputs from service industries, overhead, labor inputs, and value-added to be non-deductible. To obtain the final measure, we sum the fractions of inputs from deductible industries to obtain a single fraction for each industry that represents the share of inputs deductible under Chinese VAT rules. This object can be characterized by the following equation, where $D$ represents the set of deductible industries:

$$
\widetilde{N D} S_{s}^{U S}=1-\sum_{d \in D} \text { Input fraction }_{s d} .
$$

The U.S. NDS may measure Chinese NDS with error, which if classical, will attenuate the results. ${ }^{44}$

One concern in using the U.S. non-deductible shares to instrument for Chinese nondeductible shares is that the former may be influenced by the reform that we study via trade connections between the United States and China. We address this issue by showing that 2SLS results are robust when we exclude sectors for which trade exposure, measured as the share of U.S. imports or exports from/to China, is high. See Appendix Table A.2.

We also report 2SLS and reduced form estimates using the non-deductible shares from Mexico and South Korea in Appendix Table A.4. Because of the small magnitude of the

\footnotetext{
${ }^{44} \mathrm{~A}$ list of sectors and the estimated NDS is available upon request.
} 
Kleibergen-Paap F-statistic for the Mexico instrument (7.828) (see Panel A), we compute 95\% confidence intervals that account for weak instruments and heteroskedasticity using the method provided by Chernozhukov and Hansen (2008). They are at the bottom of the Panel A. In Panel B, we report similar statistics for the South Korea instrument for consistency. The estimates are qualitatively similar to the U.S. instrumented estimates. The precision varies across estimates.

We report the correlations among sectoral non-deductible shares from China and other countries: the United States (2007), Mexico (2000) and South Korea (2000) in Appendix Table A.3.

\section{F A Simple Model of VAT Enforcement}

\section{F.1 Benchmark}

We present here a simple model that generates all of the main dynamic effects. In the simple benchmark case, we begin by considering one sector, populated by identical, perfectly competitive firms. We assume that all firms in the given sector have the CobbDouglas technology $k^{\alpha} l^{1-\alpha}$ and factor prices of $k$ and $l$ are given by $r$ and $w$. The pre-tax price of output of the sector is $q$, and the tax-inclusive price of the output of the sector is $p$, with $q=(1+\tau) p$. Demand for the output of the sector is given by $y=q^{-\sigma}$ where $\sigma>0$ is the elasticity of demand.

We assume that there are three periods. In period 0 , there is no tax on the sector, $\tau_{0}=0$. The tax is introduced in period 1 , and $\tau_{2}=\tau_{1}$. Period 1 represents "short run", when only one factor, $l$, can be adjusted freely. Period 2 represents "long run", when both factors can be adjusted. We assume that neither $k$ nor $l$ can be deducted from VAT, so that VAT is a pure sales tax. In addition, we assume that the sector is "small", so that $r$ and $w$ are not affected by the introduction of taxes on the given sector. Sector prices $q$ and $p$ will naturally be affected by taxation. 
There are a few important points regarding these assumptions. (i) It is straightforward to write a full GE model with multiple sectors, so that taxes on sector $i$ are economy-wide and affect $r, w$. It requires much more algebra, but the results are the same as in this model, just less transparent. (ii) It is similarly straightforward to add intermediate inputs that can be deducted from the VAT, so that technology is $k^{\alpha} l^{1-\alpha-\beta} x^{\beta}$, where $x$ is the deductible input. All the results from the simpler model below will hold, but again there will be more algebra, and, moreover, one must take a stand on whether $x$ is adjusted in the long or short run. After we present the baseline model, we will show that all of the main insights follow through with extensions, and demonstrate that the results follow through under monopolistic competition.

Also note that while we will refer to $k$ as capital in the model, it does not correspond to the "assets" in the data (which do not change much), but rather to inputs that firms can change over time (e.g. intermediate inputs). Later, we will extend this model to three factors, one of which can be adjusted in period 1 and 2, another in period 2 only, and third that can never to be changed. All the key results will hold.

\section{F.1.1 Period 0}

Consider the cost function in period 0 :

$$
\begin{aligned}
C_{0}(y) & =\min _{k, l} r k+w l, \\
\text { s.t. } y & =k^{\alpha} l^{1-\alpha} .
\end{aligned}
$$

The first order conditions will be:

$$
\begin{aligned}
& {[k]: r=\eta \alpha k^{\alpha-1} l^{1-\alpha},} \\
& {[l]: w=\eta(1-\alpha) k^{\alpha} l^{-\alpha} .}
\end{aligned}
$$


These conditions yield the optimal capital-labor ratio:

$$
\frac{k_{0}}{l_{0}}=\frac{\alpha}{1-\alpha} \frac{w}{r}
$$

We can also obtain marginal costs:

$$
C_{0}^{\prime}(y)=\eta=\frac{r}{\alpha k^{\alpha-1} l^{1-\alpha}} .
$$

In equilibrium, we have

$$
C_{0}^{\prime}\left(y_{0}\right)=\frac{r}{\alpha\left(\frac{\alpha}{1-\alpha} \frac{w}{r}\right)^{\alpha-1}} \equiv \omega
$$

where $\omega$ does not depend on anything under firm's control.

When firms are perfectly competitive, their tax-inclusive price is equal to their marginal cost:

$$
p_{0}=C_{0}^{\prime}\left(y_{0}\right) .
$$

Consumer demand gives $y_{0}=q_{0}^{-\sigma}=p_{0}^{-\sigma}$. We substitute this object into the expression above to obtain

$$
y_{0}^{-1 / \sigma}=C_{0}^{\prime}\left(y_{0}\right) .
$$

The solution to this equation characterizes the output in period 0. In particular, we have

$$
y_{0}=\omega^{-\sigma} .
$$

Since $y_{0}=k_{0}^{\alpha} l_{0}^{1-\alpha}=\left(\frac{k_{0}}{l_{0}}\right)^{\alpha} l_{0}=\left(\frac{\alpha}{1-\alpha} \frac{w}{r}\right)^{\alpha} l_{0}$, we also obtain an expression for labor:

$$
l_{0}=\omega^{-\sigma}\left(\frac{\alpha}{1-\alpha} \frac{w}{r}\right)^{\alpha} .
$$

We can find $k_{0}$ and $p_{0}$ from the above equations. 


\section{F.1.2 Short-run equilibrium}

Suppose a VAT is introduced. Since under our assumptions, firms cannot deduct anything, so the VAT is equivalent to a sales tax. Suppose that in the short run, the firm cannot adjust $k$, so that $k_{1}=k_{0}$.

Then we have

$$
\begin{aligned}
& C_{1}(y)=\min _{l} r k_{0}+w l, \\
& \text { s.t. } y=k_{0}^{\alpha} l^{1-\alpha},
\end{aligned}
$$

which gives

$[l]: w=\eta(1-\alpha) k_{0}^{\alpha} l^{-\alpha}$.

Therefore, marginal costs are

$$
C_{1}^{\prime}(y)=\eta=\frac{w}{(1-\alpha) k_{0}^{\alpha} l^{-\alpha}} .
$$

Competition gives

$$
p_{1}=C_{1}^{\prime}(y)
$$

The demand is determined by the pre-tax price $q_{1}=(1+\tau) p_{1}$. Hence, the equilibrium condition is

$$
y_{1}^{-1 / \sigma}=q_{1}=(1+\tau) C^{\prime}\left(y_{1}\right) .
$$

We are interested in deriving the effect of taxation on inputs, prices, sales, tax revenues, and TFPR. The sales that we observe in the data are qy; tax revenues are $\tau p y$; and TFPR is $\frac{q y}{k^{\alpha} l^{1-\alpha}}=q$.

Lemma 1. In the short run, $y_{1}<y_{0}, p_{1}<p_{0}, l_{1}<l_{0}, q_{1}>q_{0}$, TFPR $R_{1}>T F P R_{0}$, and taxes $_{1}>$ taxes $_{0}=0$. If $\sigma>1$, then sales ${ }_{1}<$ sales $_{0}$.

Proof. Suppose $y_{1} \geq y_{0}$. Then $l_{1} \geq l_{0}$, and hence $C_{1}^{\prime}\left(y_{1}\right) \geq C_{0}^{\prime}\left(y_{0}\right)$. This implies that 
$p_{1} \geq p_{0}$. But $y_{1}=\left[(1+\tau) p_{1}\right]^{-\sigma}$, so $y_{1}$ and $p_{1}$ must go in the opposite directions, a contradiction. Therefore, $y_{1}<y_{0}$.

$y_{1}<y_{0}$ implies $l_{1}<l_{0}, C_{1}^{\prime}\left(y_{1}\right)<C_{0}^{\prime}\left(y_{0}\right), p_{1}<p_{0}$. From $y_{1}=q_{1}^{-\sigma}$ we get $q_{1}>q_{0}$.

Tax revenues are $\tau p_{1} y_{1}=\tau(1+\tau)^{-\sigma} p_{1}^{1-\sigma}>0$, so tax revenues increase.

Sales are $q_{1} y_{1}=q_{1}^{1-\sigma}$, they decline if $\sigma>1$.

Labor goes down $l_{1}<l_{0}$.

Capital does not change $k_{1}=k_{0}$.

TFPR is equal to $q$ in this model, so TFPR goes up.

For the next section, we need to find explicitly $l_{1}$. From the previous equation, we get that

$$
\left[k_{0}^{\alpha} l_{1}^{1-\alpha}\right]^{-1 / \sigma}=(1+\tau) \frac{w}{(1-\alpha) k_{0}^{\alpha} l_{1}^{-\alpha}}
$$

\section{F.1.3 Long-run Equilibrium}

Now consider the long-run equilibrium, when capital can also be adjusted. Therefore $C_{2}(y)=C_{0}(y)$ (the cost function is the same) and in the long run we have

$$
\frac{k_{2}}{l_{2}}=\frac{\alpha}{1-\alpha} \frac{w}{r}=\frac{k_{0}}{l_{0}}
$$

This gives us

$$
C_{2}^{\prime}\left(y_{2}\right)=C_{0}^{\prime}\left(y_{0}\right)>C_{1}^{\prime}\left(y_{1}\right)
$$

Therefore,

$$
p_{2}=p_{0}>p_{1} \text {. }
$$


Since

$$
\begin{aligned}
& q_{2}=(1+\tau) p_{2}, \\
& q_{1}=(1+\tau) p_{1}>p_{0}, \\
& q_{0}=p_{0},
\end{aligned}
$$

this implies that

$$
\begin{gathered}
q_{2}>q_{1}>q_{0}, \\
T F P R_{2}>T F P R_{1}>T F P R_{0} .
\end{gathered}
$$

Remark 2. The intuition behind this result is as follows: since not all factors can be adjusted immediately, the marginal costs fall: there is too much capital relative to labor in the short run, so the marginal cost of labor (the only factor that can be adjusted in period 1) is low. Therefore, the tax-inclusive price falls, although less than one for one with the tax rate, so that pre-tax price $q$ increases. Over time, as firms adjust other factors, their marginal costs rise. This implies that $p$ rises, and therefore, $q$ rises even further. Since TFPR is just q, the same is true about TFPR.

Demand is

$$
y_{2}=\left[(1+\tau) p_{2}\right]^{-\sigma}<\left[(1+\tau) p_{1}\right]^{-\sigma}<y_{1} .
$$

Therefore,

$$
y_{2}<y_{1}<y_{0}
$$

Sales are $q y=q^{1-\sigma}$. Therefore, if $\sigma>1$, we have

$$
\begin{gathered}
q_{2}^{1-\sigma}<q_{1}^{1-\sigma}<q_{0}^{1-\sigma} \\
\text { sales }_{2}<\text { sales }_{1}<\text { sales }_{0} .
\end{gathered}
$$


Tax revenues are $\tau p y=\tau \frac{p}{q} q y=\frac{\tau}{1+\tau} \times$ sales. Since $\tau_{0}=0, \tau_{1}=\tau_{2}>0$, this gives us, if $\sigma>1$, that

$$
0=\operatorname{taxes}_{0}<\operatorname{taxes}_{2}<\operatorname{taxes}_{1}
$$

Remark 3. The intuition behind these results comes from the previous remark and the assumption that $\sigma>1$. As $q$ increases in each period, $y$ must fall in each period. If demand is elastic, y falls faster than $q$ rises, which implies that sales, qy, fall. Since tax revenues are $\frac{\tau_{t}}{1+\tau_{t}} \times$ sales $_{t}$, it first increases between periods 0 and 1 (since taxes are increased from 0 to $\tau$ ) and then falls between periods 1 and 2 (since sales fall between periods 1 and 2).

Finally, we examine what happens to labor. We have

$$
l_{0}>l_{1} \text { and } l_{0}>l_{2}
$$

The remaining comparison of interest is between $l_{1}$ and $l_{2}$.

In both cases, we have $y^{-1 / \sigma}=(1+\tau) C^{\prime}(y)$. Thus, we have

$$
\begin{aligned}
& l_{1}^{(\alpha-1) / \sigma-\alpha}=(1+\tau) \frac{w}{(1-\alpha)} k_{0}^{\alpha / \sigma-\alpha}, \\
& l_{2}^{(\alpha-1) / \sigma-\alpha}=(1+\tau) \frac{w}{(1-\alpha)} k_{2}^{\alpha / \sigma-\alpha} .
\end{aligned}
$$

We must have $k_{2}<k_{0}\left(\right.$ since $k_{2} / l_{2}=k_{0} / l_{0}$ and $\left.k_{2}\left(k_{2} / l_{2}\right)^{\alpha-1}=y_{2}<y_{0}=k_{0}\left(k_{0} / l_{0}\right)^{\alpha-1}\right)$. Therefore, if $\sigma>1$, we have $k_{2}^{\alpha / \sigma-\alpha}>k_{0}^{\alpha / \sigma-\alpha}$ and therefore $l_{2}^{(\alpha-1) / \sigma-\alpha}>l_{1}^{(\alpha-1) / \sigma-\alpha}$. Since $\alpha<1$, this implies that $l_{2}<l_{1}$. Therefore we have

$$
l_{0}>l_{1}>l_{2}
$$

Remark 4. The intuition for this result comes from the following observation. We know from the Le Chatelier Principle (Samuelson, 1949) that the short-run elasticity of labor 
should be smaller than the long-run elasticity of labor (because capital can also be adjusted in the long run) holding pre-tax prices fixed. This effect implies that labor should react even more in the long run to the tax change than in the short run. In our setting, there is an offsetting effect, since the pre-tax price increases which, all things being equal, calls for more inputs. If demand is elastic, prices react little to changes in output, and the first effect dominates.

\section{F.1.4 Empirical Implications}

This model has several empirically testable implications. First, tax revenues will increase from period zero to period one, and then decline in period 2 to a level between the levels of period 0 and one: $0=\operatorname{taxes}_{0}<\operatorname{taxes}_{2}<\operatorname{taxes}_{1}$. Second, the pre-tax price, or $T F P R$, increases every period, $q_{2}>q_{1}>q_{0}$. Third, sales decline each period, $q_{2} y_{2}<q_{1} y_{1}<q_{0} y_{0}$. Fourth, labor inputs decline each period, $l_{0}>l_{1}>l_{2}$ and $k_{0} \geq k_{1}>k_{2}$. The empirical analysis will examine whether these implications are borne out in the data.

In the following sections, we show that these results hold when we introduce a third deductible good, allow for monopolistic competition, and endogenize input prices.

\section{F.2 Intermediate Goods}

Suppose we have technology $k^{\alpha} l^{1-\alpha-\beta} x^{\beta}$ where $x$ can be deducted from the VAT. Let the price of $x$ be $z$. The profits of the firm without VAT are

$$
q y-r k-w l-z x,
$$

and profits with VAT tax $\tau$ are

$$
\begin{aligned}
& (1-\tau)[q y-z x]-r k-w l, \\
= & (1-\tau) q y-r k-w l-(1-\tau) z x .
\end{aligned}
$$


Note that we have changed the pricing convention. Before, we used $(1+\tau) p=q$, where $p$ is tax-inclusive price. Now we use $p=(1-\tau) q$, where $q$ is pre-tax price. The connection to the data is more clear with this notation, since we directly observe $q$.

\section{F.2.1 Period 0}

Consider the cost function in period 0:

$$
\begin{aligned}
C_{0}(y) & =\min _{k, l, x} r k+w l+z x, \\
\text { s.t. } y & =k^{\alpha} l^{1-\alpha-\beta} x^{\beta} .
\end{aligned}
$$

It obviously gives

$[k]: r=\omega \alpha k^{\alpha-1} l^{1-\alpha-\beta} x^{\beta}$,

$[l]: w=\omega(1-\alpha-\beta) k^{\alpha} l^{-\alpha-\beta} x^{\beta}$,

$[x]: z=\omega \beta k^{\alpha} l^{1-\alpha-\beta} x^{\beta-1}$.

This gives the optimal input ratio

$$
\begin{aligned}
& \frac{k_{0}}{l_{0}}=\frac{\alpha}{1-\alpha-\beta} \frac{w}{r}, \\
& \frac{x_{0}}{l_{0}}=\frac{\beta}{1-\alpha-\beta} \frac{w}{z} .
\end{aligned}
$$

We also have marginal costs

$$
\begin{aligned}
C_{0}^{\prime}\left(y_{0}\right) & =\omega_{0}=\frac{w}{(1-\alpha-\beta) k_{0}^{\alpha} l_{0}^{-\alpha-\beta} x_{0}^{\beta}} \\
& =\frac{w}{(1-\alpha-\beta)\left(\frac{k_{0}}{l_{0}}\right)^{\alpha}\left(\frac{x_{0}}{l_{0}}\right)^{\beta}} \\
& =\frac{w}{(1-\alpha-\beta)\left(\frac{\alpha}{1-\alpha-\beta} \frac{w}{r}\right)^{\alpha}\left(\frac{\beta}{1-\alpha-\beta} \frac{w}{z}\right)^{\beta}} .
\end{aligned}
$$

Competitive firms set the tax-inclusive price to equal its marginal cost. Since there 
are no taxes in period 0 , we have

$$
q_{0}=\omega_{0}
$$

Then, the first order conditions immediately imply

$$
\begin{aligned}
& r k_{0}=\alpha q_{0} y_{0}, \\
& z x_{0}=\beta q_{0} y_{0}, \\
& w l_{0}=(1-\alpha-\beta) q_{0} y_{0} .
\end{aligned}
$$

Finally, the quantities are determined from the downward sloping demand curve

$$
y_{0}=q_{0}^{-\sigma}
$$

This equation gives

$$
\begin{aligned}
\left(\frac{k_{0}}{l_{0}}\right)^{\alpha}\left(\frac{x_{0}}{l_{0}}\right)^{\beta} l_{0} & =\left[\frac{w}{(1-\alpha-\beta)\left(\frac{k_{0}}{l_{0}}\right)^{\alpha}\left(\frac{x_{0}}{l_{0}}\right)^{\beta}}\right]^{-\sigma}, \\
l_{0} & =\left(\frac{w}{1-\alpha-\beta}\right)^{-\sigma}\left(\frac{k_{0}}{l_{0}}\right)^{\alpha(\sigma-1)}\left(\frac{x_{0}}{l_{0}}\right)^{\beta(\sigma-1)},
\end{aligned}
$$

or

$$
l_{0}=\left(\frac{w}{1-\alpha-\beta}\right)^{-\sigma}\left(\frac{\alpha}{1-\alpha-\beta} \frac{w}{r}\right)^{\alpha(\sigma-1)}\left(\frac{\beta}{1-\alpha-\beta} \frac{w}{z}\right)^{\beta(\sigma-1)} .
$$

It then follows that

$$
\begin{aligned}
k_{0} & =\frac{\alpha}{1-\alpha-\beta} \frac{w}{r} l_{0}, \\
x_{0} & =\frac{\beta}{1-\alpha-\beta} \frac{w}{z} l_{0} .
\end{aligned}
$$




\section{F.2.2 Period 2}

We analyze period 2 before period 1 , since period 2 is almost identical to period 0 . With VAT, the firm's profits are

$$
\begin{aligned}
& (1-\tau)[q y-z x]-r k-w l, \\
= & (1-\tau) q y-r k-w l-(1-\tau) z x .
\end{aligned}
$$

So the cost function is

$$
\begin{aligned}
& C_{2}(y)=\min _{k, l, x} r k+w l+(1-\tau) z x, \\
& \text { s.t. } y=k^{\alpha} l^{1-\alpha-\beta} x^{\beta} .
\end{aligned}
$$

and now the tax-inclusive price is equal to the marginal cost:

$$
\begin{aligned}
(1-\tau) q_{2} & =C_{2}^{\prime}\left(y_{2}\right)=\omega_{2} \\
q_{2} & =\frac{C_{2}^{\prime}\left(y_{2}\right)}{1-\tau}=\frac{\omega_{2}}{1-\tau} .
\end{aligned}
$$

So we have

$$
\begin{aligned}
\frac{k_{2}}{l_{2}}=\frac{\alpha}{1-\alpha-\beta} \frac{w}{r} \\
\frac{x_{2}}{l_{2}}=\frac{\beta}{1-\alpha-\beta} \frac{w}{(1-\tau) z} . \\
\omega_{2}=\frac{w}{(1-\alpha-\beta)\left(\frac{k_{2}}{l_{2}}\right)^{\alpha}\left(\frac{x_{2}}{l_{2}}\right)^{\beta}} \\
=\frac{w}{(1-\alpha-\beta)\left(\frac{\alpha}{1-\alpha-\beta} \frac{w}{r}\right)^{\alpha}\left(\frac{\beta}{1-\alpha-\beta} \frac{w}{(1-\tau) z}\right)^{\beta}} \\
=(1-\tau)^{\beta} \omega_{0} .
\end{aligned}
$$


Finally,

$$
y_{2}=q_{2}^{-\sigma}=\left(\frac{\omega_{2}}{1-\tau}\right)^{-\sigma}
$$

gives

$$
\begin{aligned}
\left(\frac{k_{2}}{l_{2}}\right)^{\alpha}\left(\frac{x_{2}}{l_{2}}\right)^{\beta} l_{2} & =(1-\tau)^{\sigma}\left[\frac{w}{(1-\alpha-\beta)\left(\frac{k_{2}}{l_{2}}\right)^{\alpha}\left(\frac{x_{2}}{l_{2}}\right)^{\beta}}\right],{ }^{-\sigma} \\
l_{2} & =(1-\tau)\left(\frac{w}{1-\alpha-\beta}\right)^{-\sigma}\left(\frac{k_{2}}{l_{2}}\right)^{\alpha(\sigma-1)}\left(\frac{x_{2}}{l_{2}}\right),{ }^{\beta(\sigma-1)}
\end{aligned}
$$

or

$$
\begin{aligned}
l_{2} & =(1-\tau)^{\sigma(1-\beta)+\beta}\left(\frac{w}{1-\alpha-\beta}\right)^{-\sigma}\left(\frac{\alpha}{1-\alpha-\beta} \frac{w}{r}\right)^{\alpha(\sigma-1)}\left(\frac{\beta}{1-\alpha-\beta} \frac{w}{z}\right)^{\beta(\sigma-1)} \\
& =(1-\tau)^{\sigma(1-\beta)+\beta} l_{0} .
\end{aligned}
$$

Similarly, we have

$$
\begin{aligned}
k_{2} & =\frac{\alpha}{1-\alpha-\beta} \frac{w}{r} l_{2}=(1-\tau)^{\sigma(1-\beta)+\beta} k_{0}, \\
x_{2} & =\frac{\beta}{1-\alpha-\beta} \frac{w}{(1-\tau) z} l_{2}=(1-\tau)^{(\sigma-1)(1-\beta)+\beta} x_{0} .
\end{aligned}
$$

This result generates clear predictions about the long run.

Lemma 5. Suppose $\sigma>1$. Then,
1. $T F P R_{2}>T F P R_{0}$,
2. sales $_{2}<$ sales $_{0}$,
3. $k_{2}<k_{0}, x_{2}<x_{0}, l_{2}<l_{0}, \omega_{2}<\omega_{0}$,
4. $0=$ taxes $_{0}<$ taxes $_{2}$. 
Proof. 1. In our model TFPR $\equiv \frac{q y}{k^{\alpha} l^{1-\alpha-\beta} x^{\beta}}=q$. We have

$$
q_{2}=\frac{\omega_{2}}{1-\tau}=\frac{(1-\tau)^{\beta} \omega_{0}}{1-\tau}=(1-\tau)^{(\beta-1)} q_{0}>q_{0}
$$

2. In our model, sales $=q y=q^{1-\sigma}$. We have, when $\sigma>1$,

$$
q_{2}^{1-\sigma}=\left[(1-\tau)^{(\beta-1)} q_{0}\right]^{1-\sigma}=(1-\tau)^{(1-\beta)(\sigma-1)} q_{0}^{1-\sigma}<q_{0}^{1-\sigma}
$$

3. We have

$$
\frac{k_{2}}{k_{0}}=\frac{l_{2}}{l_{0}}=(1-\tau)^{\sigma(1-\beta)+\beta}<1
$$

and

$$
\frac{x_{2}}{x_{0}}=(1-\tau)^{(\sigma-1)(1-\beta)+\beta}<1 .
$$

Note that the latter follows from $\sigma>1$ and we showed the result about $\omega$ earlier.

4. Note that in our model, collected taxes are taxes $=\tau[q y-z x]$. So

$$
\text { taxes }_{2}=\tau\left[q_{2} y_{2}-z x_{2}\right]=\tau\left[q_{2} y_{2}-\beta q_{2} y_{2}\right]=\tau(1-\beta) q_{2} y_{2}>0=\text { taxes }_{0}
$$

\section{F.2.3 Period 1}

Now consider period 1 problem. We assume that intermediate goods can be adjusted in period 1 , which simplifies the analysis. ${ }^{45}$

We have

$$
\begin{aligned}
C_{1}(y) & =\min _{l, x} r k_{0}+w l+(1-\tau) z x, \\
\text { s.t. } y & =k_{0}^{\alpha} l^{1-\alpha-\beta} x^{\beta} .
\end{aligned}
$$

\footnotetext{
${ }^{45}$ If they cannot, there is a lot more algebra involved although the result about taxes will hold under additional assumptions about the parameters.
} 
Which gives

$[l]: w=\omega(1-\alpha-\beta) k_{0}^{\alpha} l^{-\alpha-\beta} x^{\beta}$,

$[x]:(1-\tau) z=\omega \beta k_{0}^{\alpha} l^{1-\alpha-\beta} x^{\beta-1}$.

We have

$$
\frac{x_{1}}{l_{1}}=\frac{\beta}{1-\alpha-\beta} \frac{w}{(1-\tau) z} .
$$

As before, we have

$$
q_{1}=\frac{C_{1}^{\prime}\left(y_{1}\right)}{1-\tau}=\frac{\omega_{1}}{1-\tau}
$$

Hence, we have

$$
\begin{aligned}
w l_{1} & =(1-\alpha-\beta)(1-\tau) q_{1} y_{1}, \\
(1-\tau) z x_{1} & =\beta(1-\tau) q_{1} y_{1} .
\end{aligned}
$$

The marginal costs are

$$
\begin{aligned}
\omega_{1} & =C_{1}^{\prime}\left(y_{1}\right)=\frac{1}{1-\alpha-\beta} \frac{w}{k_{0}^{\alpha} l_{1}^{-\alpha-\beta} x_{1}^{\beta}} \\
& =\frac{1}{1-\alpha-\beta} \frac{w}{k_{0}^{\alpha} l_{1}^{-\alpha}\left(\frac{x_{1}}{l_{1}}\right)^{\beta}} .
\end{aligned}
$$

We find $l_{1}$ as before, using the demand curve:

$$
\begin{aligned}
y_{1} & =\left[\frac{\omega_{1}}{1-\tau}\right]^{-\sigma} \\
k_{0}^{\alpha} l_{1}^{1-\alpha}\left(\frac{x_{1}}{l_{1}}\right)^{\beta} & =(1-\tau)^{\sigma}\left[\frac{1}{1-\alpha-\beta} \frac{w}{k_{0}^{\alpha} l_{1}^{-\alpha}\left(\frac{x_{1}}{l_{1}}\right)^{\beta}}\right]^{-\sigma} .
\end{aligned}
$$


Therefore,

$$
\begin{aligned}
l_{1}^{1-\alpha+\sigma \alpha} & =(1-\tau)^{\sigma}\left(\frac{w}{1-\alpha-\beta}\right)^{-\sigma} k_{0}^{\alpha(\sigma-1)}\left(\frac{x_{1}}{l_{1}}\right)^{\beta(\sigma-1)} \\
& =(1-\tau)^{\sigma}\left(\frac{w}{1-\alpha-\beta}\right)^{-\sigma} k_{0}^{\alpha(\sigma-1)}\left(\frac{\beta}{1-\alpha-\beta} \frac{w}{(1-\tau) z}\right)^{\beta(\sigma-1)} \\
& =(1-\tau)^{\sigma+\beta(1-\sigma)}\left(\frac{w}{1-\alpha-\beta}\right)^{-\sigma} k_{0}^{\alpha(\sigma-1)}\left(\frac{\beta}{1-\alpha-\beta} \frac{w}{z}\right)^{\beta(\sigma-1)} .
\end{aligned}
$$

This equation gives the following useful intermediate result.

Lemma 6. Suppose $\sigma>1$. Then
1. $l_{0}>l_{1}>l_{2}$,
2. $y_{0}>y_{1}>y_{2}$,
3. $\omega_{1}<\omega_{2}<\omega_{0}$ and $\omega_{0}<\frac{\omega_{1}}{1-\tau}<\frac{\omega_{2}}{1-\tau}$.

Proof. 1. The previous equation should also hold in period 2 when capital stock is set at its optimal value $k_{2}$, i.e.

$$
l_{2}^{1-\alpha+\sigma \alpha}=(1-\tau)^{\sigma+\beta(1-\sigma)}\left(\frac{w}{1-\alpha-\beta}\right)^{-\sigma} k_{2}^{\alpha(\sigma-1)}\left(\frac{\beta}{1-\alpha-\beta} \frac{w}{z}\right)^{\beta(\sigma-1)}
$$

which implies

$$
\begin{aligned}
\left(\frac{l_{2}}{l_{1}}\right)^{1+(\sigma-1) \alpha} & =\left(\frac{k_{2}}{k_{0}}\right)^{\alpha(\sigma-1)} \\
\frac{l_{2}}{l_{1}} & =\left(\frac{k_{2}}{k_{0}}\right)^{\frac{\alpha(\sigma-1)}{1+\alpha(\sigma-1)}} .
\end{aligned}
$$

Since $k_{2}<k_{0}$, this implies $l_{2}<l_{1}$. 
Similarly, the analogous equation should hold in period 0 (when $\tau=0$ ) so that

$$
\begin{aligned}
\left(\frac{l_{1}}{l_{0}}\right)^{1+(\sigma-1) \alpha} & =(1-\tau)^{\sigma+\beta(1-\sigma)}=(1-\tau)^{\sigma(1-\beta)+\beta} \\
\frac{l_{1}}{l_{0}} & =(1-\tau)^{\frac{\sigma(1-\beta)+\beta}{1+(\sigma-1) \alpha}}<1 .
\end{aligned}
$$

Therefore $l_{1}<l_{0}$.

2. For output, we have

$$
\begin{aligned}
\frac{y_{1}}{y_{0}} & =\left(\frac{l_{1}}{l_{0}}\right)^{1-\alpha}\left(\frac{x_{1} / l_{1}}{x_{0} / l_{0}}\right)^{\beta} \\
& =(1-\tau)^{\frac{\sigma(1-\beta)+\beta}{1+(\sigma-1) \alpha}(1-\alpha)-\beta} \\
& =(1-\tau)^{\frac{1-\alpha-\beta}{1+(\sigma-1) \alpha}}<1 .
\end{aligned}
$$

Therefore, $y_{1}<y_{0}$.

Using the fact that $\frac{x_{1}}{l_{1}}=\frac{x_{2}}{l_{2}}$, we have

$$
\frac{y_{2}}{y_{1}}=\frac{k_{2}^{\alpha} l_{2}^{1-\alpha}}{k_{0}^{\alpha} l_{1}^{1-\alpha}}
$$

Since we showed already that $\frac{k_{2}}{k_{0}}<1$ and $\frac{l_{2}}{l_{1}}<1$, this implies that $y_{2}<y_{1}$.

3. For marginal costs, we have

$$
\begin{aligned}
\frac{\omega_{1}}{\omega_{2}} & =\frac{\frac{1}{1-\alpha-\beta} \frac{w}{k_{0}^{\alpha} l_{1}^{-\alpha}\left(\frac{x_{1}}{l_{1}}\right)^{\beta}}}{w}=\left(\frac{k_{2}}{k_{0}} / \frac{l_{2}}{l_{1}}\right)^{\alpha}=\left(\frac{k_{2}}{k_{0}}\right)^{\alpha\left[1-\frac{\alpha(\sigma-1)}{1+(\sigma-1) \alpha}\right]} \\
& =\left(\frac{k_{2}}{k_{0}}\right)^{\frac{\alpha}{1+\alpha(\sigma-1)}}<1 .
\end{aligned}
$$

Thus, $\omega_{1}<\omega_{2}$. We showed already that $\omega_{2}<\omega_{0}$, which implies $\omega_{1}<\omega_{0}$.

Moreover,

$$
\frac{\omega_{1}}{\omega_{0}}=\frac{\frac{1}{1-\alpha-\beta} \frac{w}{k_{0}^{\alpha} l_{1}^{-\alpha-\beta} x_{1}^{\beta}}}{\frac{1}{1-\alpha-\beta} \frac{w}{k_{0}^{\alpha} l_{0}^{-\alpha-\beta} x_{0}^{\beta}}}=\frac{l_{0}^{-\alpha-\beta} x_{0}^{\beta}}{l_{1}^{-\alpha-\beta} x_{1}^{\beta}}=\left(\frac{l_{1}}{l_{0}}\right)^{\alpha}(1-\tau)^{\beta}
$$


or

$$
\frac{\omega_{1} /(1-\tau)}{\omega_{0}}=(1-\tau)^{\frac{\sigma(1-\beta)+\beta}{1+(\sigma-1) \alpha} \alpha-(1-\beta)}=(1-\tau)^{-\frac{1-\beta-\beta \alpha}{1+\alpha(\sigma-1)}}
$$

which implies that $\frac{\omega_{1}}{1-\tau}>\omega_{0}$.

With this lemma, we can extend all the results of the simple model.

Lemma 7. Suppose $\sigma>1$. Then

1. $T F P R_{2}>T F P R_{1}>T F P R_{0}$,

2. sale $_{0}>$ sales $_{1}>$ sales $_{2}$,

3. $0=$ taxes $_{0}<$ taxes $_{2}<\operatorname{taxes}_{1}$.

Proof. 1. Since $T F P R=q=\frac{\omega}{1-\tau}$, from the previous lemma we have

$$
q_{0}<q_{1}<q_{2}
$$

2. Sales are $q y=q^{1-\sigma}$, so with $\sigma>1$ we have, from the previous equation

$$
\text { sale }_{0}>\text { sales }_{1}>\text { sales }_{2} .
$$

3. Taxes revenues are $\tau(q y-z x)$. Since

$$
\frac{z x_{1}}{q_{1} y_{1}}=\frac{z x_{2}}{q_{2} y_{2}}=\beta
$$

it becomes

$$
\text { taxes }=(1-\beta) \tau \times \text { sales }
$$

Since $\tau_{0}=0$, and sales $_{1}>$ sales $_{2}$, we get

$$
0=\operatorname{taxes}_{0}<\operatorname{taxes}_{2}<\operatorname{taxes}_{1}
$$




\section{F.3 Monopolistic competition}

Here, we will extend the analysis to allow firms to have market power and set prices. We will focus on the benchmark economy without intermediate goods for simplicity.

Firms will be monopolistically-competitive, as in the Dixit-Stiglitz model. There is a continuum of firms and each firm produces a differentiated good. ${ }^{46}$ Consumers buy all these goods, so their budget constraint is

$$
\int_{0}^{1} q(i) c(i) d i=w l+m
$$

where $m$ is non-labor income.

Consumer preferences in each period are given by

$$
\frac{Y^{1-1 / \sigma}}{1-1 / \sigma}-l
$$

where

$$
Y=\left(\int_{0}^{1} y(i)^{1-1 / \varepsilon} d i\right)^{\frac{\varepsilon}{\varepsilon-1}}
$$

Here, $\varepsilon>1$ is the elasticity of substitution between goods.

Standard results imply that demand for good $i$ is determined by equation

$$
y(i)=\left(\frac{q(i)}{Q}\right)^{-\varepsilon} Y
$$

where the aggregate price satisfies

$$
Q=\left(\int_{0}^{1} q(i)^{1-\varepsilon} d i\right)^{\frac{1}{1-\varepsilon}}
$$

\footnotetext{
${ }^{46}$ We assume that the variety set is $[0,1]$ because we assume that $y=Y$ and $q=Q$.
} 
The aggregate demand can be found from

$$
\begin{gathered}
\max _{Y, l} \frac{Y^{1-1 / \sigma}}{1-\sigma}-l, \\
Y Q=w l+m
\end{gathered}
$$

which gives

$$
Y^{-1 / \sigma}=Q / w .
$$

Wage $w$ can be taken to be a numeraire, and it is without loss of generality to set $w=1$.

\section{F.3.1 Firm's problem}

We will do things in "partial" equilibrium so that the interest rate $r$ is fixed (equivalent to a GE model in which there are international capital markets with a rental rate of capital given by $r$ ). We will relax this assumption in another extension. In equilibrium, firm $i$

will take for now $Q, Y$, and $r$ as given ( $w=1$ always) and chooses $q(i)$ to maximize its profits, taking into account consumer demand. So the firm in period 0 solves

$$
\max _{q, y, l, k} q y-w l-r k,
$$

s.t.

$$
\begin{aligned}
& y=\left(\frac{q}{Q}\right)^{-\varepsilon} Y, \\
& y=k^{\alpha} l^{1-\alpha} .
\end{aligned}
$$

We have

$$
\begin{aligned}
& {[l]: w=\omega(1-\alpha) k^{\alpha} l^{-\alpha},} \\
& {[k]: r=\omega \alpha k^{\alpha-1} l^{1-\alpha},} \\
& {[y]: q=\lambda+\omega,}
\end{aligned}
$$


$[q]: q y=\lambda \varepsilon\left(\frac{q}{Q}\right)^{-\varepsilon} Y$.

The first two equations give us the usual conditions

$$
\begin{aligned}
\frac{k_{0}}{l_{0}} & =\frac{\alpha}{1-\alpha} \frac{w}{r} \\
\omega_{0} & =\frac{w}{(1-\alpha) k_{0}^{\alpha} l_{0}^{-\alpha}}=\frac{w}{(1-\alpha)\left(\frac{\alpha}{1-\alpha} \frac{w}{r}\right)^{\alpha}} .
\end{aligned}
$$

Note that $\omega_{0}$ has the same meaning as before: the marginal cost of producing an extra unit of a good.

In equilibrium, since all firms are identical, we have

$$
q=Q, y=Y
$$

Therefore, the last two optimality conditions become

$$
\begin{aligned}
& q_{0}=\lambda_{0}+\omega_{0}, \\
& q_{0}=\lambda_{0} \varepsilon .
\end{aligned}
$$

This gives us

$$
q_{0}=q_{0} \varepsilon-\omega_{0} \varepsilon=\frac{\varepsilon}{\varepsilon-1} \omega_{0}
$$

This equation is the standard condition that the optimal price is equal to a markup $\frac{\varepsilon}{\varepsilon-1}>1$ times the marginal cost, $\omega_{0}$. As $\varepsilon \rightarrow \infty$, goods become more and more substitutable and we converge to the perfect competition case considered in the benchmark model.

The consumer's optimality condition $Y^{-1 / \sigma}=Q / w$ (together with normalization 
$w=1, y=Y, q=Q)$ gives

$$
y_{0}=q_{0}^{-\sigma}=\left(\frac{\varepsilon}{\varepsilon-1}\right)^{-\sigma} \omega_{0}^{-\sigma}
$$

So the analysis goes through the same way as before, except now everything is multiplied by a markup.

Given that, we will verify that markup is the same in periods 1 and 2 . In that case, then all the analysis thus far goes through without any changes.

Period 2's problem is

$$
\max _{q, y, l, k}(1-\tau) q y-w l-r k
$$

s.t.

$$
\begin{aligned}
y & =\left(\frac{q}{Q}\right)^{-\varepsilon} Y, \\
y & =k^{\alpha} l^{1-\alpha} .
\end{aligned}
$$

These give the optimality conditions.

We have

$[l]: w=\omega(1-\alpha) k^{\alpha} l^{-\alpha}$

$[k]: r=\omega \alpha k^{\alpha-1} l^{1-\alpha}$,

$[y]:(1-\tau) q=\lambda+\omega$,

$[q]:(1-\tau) q y=\lambda \varepsilon\left(\frac{q}{Q}\right)^{-\varepsilon} Y$.

So we have, as before, (the case $\beta=0$ ) from the first two equations:

$$
\omega_{2}=\omega_{0} .
$$


The last two give us

$$
q_{2}=\frac{\varepsilon}{\varepsilon-1} \frac{\omega_{2}}{1-\tau}
$$

This expression is the same as we had before, modulo a markup.

Finally, period 1 problem is

$$
\max _{q, y, l}(1-\tau) q y-w l-r k_{0}
$$

with

$$
\begin{aligned}
& {[l]: w=\omega(1-\alpha) k_{0}^{\alpha} l^{-\alpha},} \\
& {[y]:(1-\tau) q=\lambda+\omega,} \\
& {[q]:(1-\tau) q y=\lambda \varepsilon\left(\frac{q}{Q}\right)^{-\varepsilon} Y .}
\end{aligned}
$$

Note that again we have

$$
q_{1}=\frac{\varepsilon}{\varepsilon-1} \frac{\omega_{1}}{1-\tau}
$$

So the marginal costs are the same as in the baseline, and price is just a constant markup over those costs. Given that, all the steps in the proofs of the baseline economy should go through with minimal modifications.

\section{F.4 Multiple Sectors, Fixed Capital}

Now, we will assume that there are 2 sectors, and that the capital stock is in fixed net supply. Other than that, we return to our baseline model of perfect competition. So 
consumers will solve

$$
\max \mu^{\frac{1}{\sigma}} \frac{y^{1-1 / \sigma}}{1-1 / \sigma}+(1-\mu)^{\frac{1}{\sigma}} \frac{Y^{1-1 / \varepsilon}}{1-1 / \sigma}-l,
$$

s.t.

$$
q y+Q Y=w l+r \bar{k}+\Pi,
$$

where $\bar{k}$ is the total capital stock and capital letters denote "the other" sector, not affected by taxes. Here, $\mu \in(0,1)$. The case $\mu=0$ corresponds to what we have done before: sector 1 is small, so nothing there affects taxes. Here, $\Pi$ denotes profits of the firms. For simplicity, we assume that the production function is the same in the two sectors.

The capital stock is in fixed supply and is rented out by consumers to the firms at a rate $r$. If the sector-level demands for capital are $k$ and $K$, then the market clearing condition for the capital stock is

$$
k+K=\bar{k} .
$$

Once again, everything will be in units of labor, so we normalize $w=1$.

The two sectors are identical in period 0 , but the VAT tax will be applied to the first sector in period 1 .

Given our normalization, demand is again given by

$$
y=\mu q^{-\sigma}, Y=(1-\mu) Q^{-\sigma} .
$$

\section{F.4.1 Period 0}

The analysis goes like before except now $l_{0}$ is not given by

$$
\begin{aligned}
\left(\frac{k_{0}}{l_{0}}\right)^{\alpha} l_{0} & =\mu\left[\frac{w}{(1-\alpha)\left(\frac{k_{0}}{l_{0}}\right)^{\alpha}}\right]-\sigma \\
l_{0} & =\mu\left(\frac{w}{1-\alpha}\right)^{-\sigma}\left(\frac{k_{0}}{l_{0}}\right)^{\alpha(\sigma-1)},
\end{aligned}
$$


or

$$
l_{0}=\mu\left(\frac{w}{1-\alpha}\right)^{-\sigma}\left(\frac{\alpha}{1-\alpha} \frac{w}{r_{0}}\right) \alpha(\sigma-1),
$$

and

$$
\begin{aligned}
k_{0} & =\frac{\alpha}{1-\alpha} \frac{w}{r_{0}} l_{0} \\
& =\mu\left(\frac{w}{1-\alpha}\right)^{-\sigma}\left(\frac{\alpha}{1-\alpha} \frac{w}{r_{0}}\right)^{\alpha(\sigma-1)+1} .
\end{aligned}
$$

Demand in the other sector is

$$
K_{0}=(1-\mu)\left(\frac{w}{1-\alpha}\right)^{-\sigma}\left(\frac{\alpha}{1-\alpha} \frac{w}{r_{0}}\right)^{\alpha(\sigma-1)+1} .
$$

This allows us to find the rental rate $r_{0}$ from

$$
\begin{aligned}
& \mu\left(\frac{w}{1-\alpha}\right)^{-\sigma}\left(\frac{\alpha}{1-\alpha} \frac{w}{r_{0}}\right)^{\alpha(\sigma-1)+1}+(1-\mu)\left(\frac{w}{1-\alpha}\right)^{-\sigma}\left(\frac{\alpha}{1-\alpha} \frac{w}{r_{0}}\right)^{\alpha(\sigma-1)+1}=\bar{k}, \\
& \left(\frac{w}{1-\alpha}\right)^{-\sigma}\left(\frac{\alpha}{1-\alpha} \frac{w}{r_{0}}\right)^{\alpha(\sigma-1)+1}=\bar{k} \text {. }
\end{aligned}
$$

\section{F.4.2 Period 1}

In period 1, taxes are introduced but capital cannot be adjusted, so we simply assume that $r_{1}=r_{0}$. Since capital stock cannot move, the rental rate is strictly-speaking indeterminate, but small refinements of this set up should give $r_{1}=r_{0}$.

Since $(r, w)$ are the same in period 1 as in period 0 , the problems of the two sectors are unchanged. The whole characterization of the period 1 problem of the sector affected by the VAT tax goes without any changes. The labor demand in sector 1 is given by

$$
l_{1}^{1-\alpha+\sigma \alpha}=\mu(1-\tau)^{\sigma}\left(\frac{w}{1-\alpha}\right)^{-\sigma} k_{0}^{\alpha(\sigma-1)} .
$$




\section{F.4.3 Period 2}

We have, following the same steps as before

$$
\begin{aligned}
l_{2} & =\mu(1-\tau)^{\sigma}\left(\frac{w}{1-\alpha}\right)^{-\sigma}\left(\frac{\alpha}{1-\alpha} \frac{w}{r_{2}}\right)^{\alpha(\sigma-1)} \\
& =(1-\tau)^{\sigma}\left(\frac{r_{2}}{r_{0}}\right)^{\alpha(\sigma-1)} l_{0} .
\end{aligned}
$$

and

$$
\begin{aligned}
k_{2} & =\frac{\alpha}{1-\alpha} \frac{w}{r_{2}} l_{2} \\
& =\mu(1-\tau)^{\sigma}\left(\frac{w}{1-\alpha}\right)^{-\sigma}\left(\frac{\alpha}{1-\alpha} \frac{w}{r_{2}}\right)^{\alpha(\sigma-1)+1} \\
& =\left[(1-\tau)^{\sigma}\left(\frac{r_{0}}{r_{2}}\right)^{\alpha(\sigma-1)+1}\right] \mu\left(\frac{w}{1-\alpha}\right)^{-\sigma}\left(\frac{\alpha}{1-\alpha} \frac{w}{r_{0}}\right)^{\alpha(\sigma-1)+1} \\
& =\left[(1-\tau)^{\sigma}\left(\frac{r_{0}}{r_{2}}\right)^{\alpha(\sigma-1)+1}\right] k_{0} .
\end{aligned}
$$

Capital in the other sector is

$$
K_{2}=(1-\mu)\left(\frac{w}{1-\alpha}\right)^{-\sigma}\left(\frac{\alpha}{1-\alpha} \frac{w}{r_{2}}\right)^{\alpha(\sigma-1)+1} .
$$

So the market clearing condition is

$$
\left[\mu(1-\tau)^{\sigma}+(1-\mu)\right]\left(\frac{w}{1-\alpha}\right)^{-\sigma}\left(\frac{\alpha}{1-\alpha} \frac{w}{r_{2}}\right)^{\alpha(\sigma-1)+1}=\bar{k}
$$

Equivalently

$$
\begin{aligned}
{\left[\mu(1-\tau)^{\sigma}+(1-\mu)\right]\left(\frac{r_{0}}{r_{2}}\right)^{\alpha(\sigma-1)+1}\left(\frac{w}{1-\alpha}\right)^{-\sigma}\left(\frac{\alpha}{1-\alpha} \frac{w}{r_{0}}\right)^{\alpha(\sigma-1)+1} } & =\bar{k}, \\
{\left[\mu(1-\tau)^{\sigma}+(1-\mu)\right]\left(\frac{r_{0}}{r_{2}}\right)^{\alpha(\sigma-1)+1} } & =1,
\end{aligned}
$$


or

$$
(1-\tau)^{\sigma}\left(\frac{r_{0}}{r_{2}}\right)^{\alpha(\sigma-1)+1}=\frac{(1-\tau)^{\sigma}}{\mu(1-\tau)^{\sigma}+(1-\mu)} .
$$

Therefore we have

Lemma 8. $(1-\tau)^{\sigma}\left(\frac{r_{0}}{r_{2}}\right)^{\alpha(\sigma-1)+1}$ is strictly increasing in $\mu$ with

$$
(1-\tau)^{\sigma} \leq(1-\tau)^{\sigma}\left(\frac{r_{0}}{r_{2}}\right)^{\alpha(\sigma-1)+1} \leq 1
$$

with left and right inequalities holding as equality for $\mu=0$ and $\mu=1$ respectively.

Therefore, we have

Lemma 9. Suppose $\sigma>1$. Then $k_{2} \leq k_{0}, l_{2} \leq l_{1}$, sales $s_{2} \leq$ sales $_{1}$, taxes $_{2} \leq$ taxes $_{1}$, TFPR $_{2} \geq$ TFPR $R_{1}$, where inequality holds as equality only if $\mu=1$. The inequalities reverse for sector 2 .

Proof. The previous lemma and our equation for capital imply that $k_{2} \leq k_{0}$. The labor supply $l_{1}$ and $l_{2}$ can be written (see Lemma 6) as

$$
\begin{aligned}
& l_{1}^{1-\alpha+\sigma \alpha}=\mu(1-\tau)^{\sigma}\left(\frac{w}{1-\alpha}\right)^{-\sigma} k_{0}^{\alpha(\sigma-1)}, \\
& l_{2}^{1-\alpha+\sigma \alpha}=\mu(1-\tau)^{\sigma}\left(\frac{w}{1-\alpha}\right)^{-\sigma} k_{2}^{\alpha(\sigma-1)} .
\end{aligned}
$$

Therefore, $l_{2} \leq l_{1}$ with strict inequality if $\mu<1$. Since $y_{t}=k_{t}^{\alpha} l_{t}^{1-\alpha}$, and both $k$ and $l$ decrease in period $2, y_{2} \leq y_{1}$. We have sales $_{t}=q_{t} y_{t}=\mu^{\frac{1}{\sigma}} y_{t}^{\frac{\sigma-1}{\sigma}}$, therefore sales $s_{2} \leq$ sales $_{1}$. Taxes are gives by taxes $_{t}=\tau \times$ sales $_{t}$, so we get the result on sales. Since we can also write sales $_{t}=\mu q_{t}^{1-\sigma}$ and $T F P R_{t}=q_{t}$, we get that TFPR $R_{2} \geq T F P R_{1}$.

Since total capital is fixed, we must have $K_{2} \geq K_{0}$ and the same steps prove reverse inequalities for sector 2 (which obviously does not have taxes).

This step completes the proof, since we already know what happens in period 1. Note that $\mu=0$ is the same case as our baseline model (it is easier to see this if we redefine 
all variables as ratios to $\mu$ and look at the limit as $\mu \rightarrow 0)$. In this case, sector 1 is small, so that any reallocation of capital from sector 1 to sector 2 has no effect on price $r$. The lemma above shows that all the insights continue to generalize in the 2 sector GE model where interest rate $r$ is endogenously determined and is affected by the reallocation. The mechanism is the same as in the benchmark case: as long as there is some reallocation in period 2 of capital due to re-optimization, capital $k_{2}$ will decrease in period 2 , further depressing labor demand $l_{2}$ and output $y_{2}$, leading to lower sales and tax revenues in sector 1 . In the limit case, $\mu=1$, sector 2 is negligibly small and cannot absorb any capital. As a result, with fixed capital stock, rental rates $r_{2}$ must fall sufficiently to prevent any re-allocation of capital from sector 1 , in which case, period 1 and period 2 become identical. 
Table A.1: Sectors with Highest and Lowest Non-Deductible Shares

\begin{tabular}{|c|c|c|c|}
\hline \multicolumn{2}{|l|}{ Lowest Non-Deductible Share } & \multicolumn{2}{|l|}{ Highest Non-Deductible Share } \\
\hline (1) & (2) & (3) & (4) \\
\hline Sector Name & $\begin{array}{c}\text { Non-Deductible } \\
\text { Share }\end{array}$ & $\begin{array}{r}\text { Sector Name } \\
\end{array}$ & $\begin{array}{c}\text { Non-Deductible } \\
\text { Share }\end{array}$ \\
\hline Beet Sugar & 0.24 & Tobacco Leaf Re - Baking & 0.60 \\
\hline Cane Sugar & 0.24 & Other Tobacco Processing & 0.60 \\
\hline Frozen Aquatic Products Processing & 0.25 & Cigarette Manufacturing & 0.60 \\
\hline Dry Processing Of Aquatic Products & 0.25 & Caustic Soda Manufacturing & 0.56 \\
\hline Electric Light Source Manufacturing & 0.27 & Inorganic Acid Manufacturing & 0.56 \\
\hline Lamp Holder, Lampholders Manufacturing & 0.27 & Industrial Ceramics & 0.53 \\
\hline Wire And Cable Manufacturing & 0.30 & Other Ceramics & 0.53 \\
\hline Postal Machinery And Equipment Manufacturing & 0.30 & Other Stationery Manufacturing & 0.51 \\
\hline Construction Machinery Manufacturing & 0.30 & Notebook Manufacturing & 0.51 \\
\hline Sewing Machine Manufacturing & 0.30 & Stationery Manufacturing & 0.51 \\
\hline Manufacture Of Special Equipment Not Included In Other Categories & 0.30 & Lime & 0.51 \\
\hline Geological Special Equipment Manufacturing & 0.30 & Special Chemical Products Manufacturing & 0.50 \\
\hline Commercial, Catering, Service Machinery Manufacturing & 0.30 & Manufacture Of Chemical Products In Forest Products & 0.50 \\
\hline Petroleum Products & 0.31 & Explosives And Pyrotechnic Products Manufacturing & 0.50 \\
\hline Viscose Fiber Manufacturing & 0.33 & Chemical Reagents, Additives Manufacturing & 0.50 \\
\hline Acrylic Fiber Manufacturing & 0.33 & Chinese Herbal Medicine And Chinese Medicine Processing & 0.50 \\
\hline Nylon Fiber Manufacturing & 0.33 & Biological Products & 0.50 \\
\hline Polyester Fiber Manufacturing & 0.33 & Chemical Drug Manufacturing & 0.50 \\
\hline Chemical Fiber Pulp Manufacturing & 0.33 & Manufacture Of Chemical Preparations & 0.50 \\
\hline Other Synthetic Fiber Manufacturing & 0.33 & Books, Newspapers And Periodicals & 0.49 \\
\hline Vinylon Fiber Manufacturing & 0.33 & Packaging And Decoration Printing & 0.49 \\
\hline Motorcycle Manufacturing & 0.33 & Other Printing & 0.49 \\
\hline Manufacturing Of Inland Waterways & 0.33 & Copying Of Recording Medium & 0.49 \\
\hline Diving Equipment Manufacturing & 0.33 & Crude Oil Processing & 0.48 \\
\hline Manufacture Of Aids To Navigation & 0.33 & Bearing Manufacturing & 0.48 \\
\hline Motorcycle Parts And Accessories Manufacturing & 0.33 & Valve Manufacturing & 0.48 \\
\hline Manufacture Of Marine Transport Ships & 0.33 & Casting Manufacturing & 0.48 \\
\hline Luggage Manufacturing & 0.33 & Communication Terminal Equipment Manufacturing & 0.48 \\
\hline Leather Leather Garment Manufacturing & 0.33 & Switching Equipment Manufacturing & 0.48 \\
\hline Other Fur Products & 0.33 & Electronic Computer Manufacturing & 0.48 \\
\hline Leather Shoes Manufacturing & 0.33 & Radar Special Equipment And Components & 0.48 \\
\hline Fur Tanning & 0.33 & Other Electronic Equipment & 0.48 \\
\hline Fur Clothing & 0.33 & Transmission Equipment Manufacturing & 0.48 \\
\hline Wool & 0.34 & Radar Complete Machine Manufacturing & 0.48 \\
\hline Top Processing & 0.34 & Other Communication Equipment Manufacturing & 0.48 \\
\hline Wool & 0.34 & Radio And Television Equipment Manufacturing & 0.48 \\
\hline Automotive Body Manufacturing & 0.34 & Asbestos Products & 0.48 \\
\hline Special Vehicles And Modified Car Manufacturing & 0.34 & Other Refractory Products & 0.48 \\
\hline Small Car Manufacturing & 0.34 & Concrete Structural Component Manufacturing & 0.48 \\
\hline Passenger Car Manufacturing & 0.34 & Manufacture Of Waterproof Seal Building Materials & 0.48 \\
\hline Heavy Truck Manufacturing & 0.34 & Building Stone Processing & 0.48 \\
\hline Micro - Car & 0.34 & Asbestos Cement Products & 0.48 \\
\hline Ink Manufacturing & 0.34 & Brick And Tile Manufacturing & 0.48 \\
\hline Paint Manufacturing & 0.34 & Manufacture Of Lightweight Building Materials & 0.48 \\
\hline Manufacture Of Organic Chemical Materials & 0.34 & Cement Products & 0.48 \\
\hline Other Organic Chemical Products & 0.34 & Other Brick, Lime And Light Construction Materials & 0.48 \\
\hline Foam And Synthetic Leather, Synthetic Leather Manufacturing & 0.34 & Other Cement Products & 0.48 \\
\hline Other Plastic Products & 0.34 & Manufacture Of Other Basic Chemical Raw Materials & 0.48 \\
\hline Manufacture Of Daily Plastic Sundry Goods & 0.34 & Optical Glass Manufacturing & 0.47 \\
\hline Plastic Shoe Manufacturing & 0.34 & Other Glass And Glass Products & 0.47 \\
\hline
\end{tabular}

Notes: Manufacturing sectors are defined by four-digit Chinese Industrial Codes. VAT share is calculated from 1997 Chinese Input Output Tables. See the text for a detailed description. 
Table A.2: The Effect of Computerization on VAT - Robustness to Dropping U.S. Sectors Highly Exposed to Chinese Trade

\begin{tabular}{|c|c|c|}
\hline & \multicolumn{2}{|c|}{ Dependent Variable: VAT } \\
\hline & $(1)$ & $(2)$ \\
\hline & $\begin{array}{l}\text { Drop Sectors with top } 25 \% \\
\text { U.S. Exports from China / Total U.S. Exports }\end{array}$ & $\begin{array}{l}\text { Drop Sectors with top 25\% } \\
\text { U.S. Exports to China / Total U.S. Exports }\end{array}$ \\
\hline Dep Var Mean & 2,096 & 2,034 \\
\hline Non-deductible share x Post-2002 & $\begin{array}{l}1,130^{* *} \\
(496.6)\end{array}$ & $\begin{array}{l}958.7^{*} \\
(501.6)\end{array}$ \\
\hline Observations & 161,630 & 161,725 \\
\hline
\end{tabular}

Table A.3: Non-Deductible Shares across Countries

\begin{tabular}{lccc}
\hline \hline & \multicolumn{2}{c}{ Dependent Variable: Non-deductible Shares in Other Countries } \\
\cline { 2 - 4 } & $\begin{array}{c}(1) \\
(2)\end{array}$ & $\begin{array}{c}(3) \\
\text { South Korea 2000 }\end{array}$ \\
\hline Chinese Non-Deductible Share & $0.254^{* * *}$ & $0.366^{* * *}$ & $0.416^{* * *}$ \\
& $(0.0714)$ & $(0.0689)$ & $(0.0698)$ \\
Constant & $0.563^{* * *}$ & $0.437 * * *$ & $0.327^{* * *}$ \\
& $(0.0294)$ & $(0.0284)$ & $(0.0287)$ \\
Observations & & & 424 \\
R-squared & 424 & 424 & 0.078 \\
\hline
\end{tabular}

Notes: Observations are at the sector level. Each column is a univariate regression with a constant. $* * * \mathrm{p}<0.01, * *$ $\mathrm{p}<0.05, * \mathrm{p}<0.1$ 
Table A.4: The Effect of Computerization on VAT - Instrumented with Non-Deductible Shares from South Korea

\begin{tabular}{|c|c|c|c|c|}
\hline & \multicolumn{4}{|c|}{ Dependent Variables } \\
\hline & (1) & $(2)$ & (3) & (4) \\
\hline & VAT Gross & VAT Deductions & VAT & VAT/Sales \\
\hline & \multicolumn{4}{|c|}{ A. Mexico: 2SLS } \\
\hline Non-deductible share x Post-2002 & $\begin{array}{l}-6,291 \\
(8,733)\end{array}$ & $\begin{array}{l}-12,405 \\
(7,764)\end{array}$ & $\begin{array}{l}4,859^{*} \\
(2,689)\end{array}$ & $\begin{array}{c}0.0397 \\
(0.0249)\end{array}$ \\
\hline Observations & 180,071 & 180,071 & 180,071 & 180,071 \\
\hline Kleibergen-Paap F-statistic & 7.828 & 7.828 & 7.828 & 7.828 \\
\hline \multirow[t]{2}{*}{$\mathrm{CH}$ Weak-Instrument $95 \% \mathrm{CI}$} & $(-37,128 ; 12,337)$ & $(-46,673 ; 849)$ & $(476 ; 17,285)$ & $(-.0016 ; .1524)$ \\
\hline & \multicolumn{4}{|c|}{ B. South Korea: 2SLS } \\
\hline Non-deductible share x Post-2002 & $\begin{array}{c}-21,205^{* * *} \\
(7,640)\end{array}$ & $\begin{array}{c}-23,429 * * * \\
(6,925)\end{array}$ & $\begin{array}{c}1,604 \\
(1,752)\end{array}$ & $\begin{array}{c}0.0492^{* * *} \\
(0.0186)\end{array}$ \\
\hline Observations & 180,071 & 180,071 & 180,071 & 180,071 \\
\hline Kleibergen-Paap F-statistic & 18.67 & 18.67 & 18.67 & 18.67 \\
\hline \multirow[t]{2}{*}{$\mathrm{CH}$ Weak-Instrument $95 \% \mathrm{CI}$} & $(-44,791 ;-9,253)$ & $(-45,528 ;-12,951)$ & $(-2,235,5,464)$ & $(.02 ; .106)$ \\
\hline & \multicolumn{4}{|c|}{ C. Mexico: Reduced Form } \\
\hline Non-deductible share x Post-2002 & $\begin{array}{l}-1,124 \\
(1,507)\end{array}$ & $\begin{array}{l}-2,217^{*} \\
(1,203)\end{array}$ & $\begin{array}{c}868.4 * * \\
(401.9)\end{array}$ & $\begin{array}{l}0.00709 * \\
(0.00377)\end{array}$ \\
\hline Observations & 180,071 & 180,071 & 180,071 & 180,071 \\
\hline \multirow[t]{2}{*}{ R-squared } & 0.626 & 0.500 & 0.692 & 0.560 \\
\hline & \multicolumn{4}{|c|}{ D. South Korea: Reduced Form } \\
\hline Non-deductible share x Post-2002 & $\begin{array}{c}-5,084 * * * \\
(1,344)\end{array}$ & $\begin{array}{c}-5,618 * * * \\
(1,100)\end{array}$ & $\begin{array}{c}384.6 \\
(428.9)\end{array}$ & $\begin{array}{c}0.0118^{* * *} \\
(0.00339)\end{array}$ \\
\hline Observations & 180,071 & 180,071 & 180,071 & 180,071 \\
\hline R-squared & 0.627 & 0.500 & 0.692 & 0.560 \\
\hline
\end{tabular}

Notes: The sample is a balanced panel of firms covering 1998-2007. All regressions include firm fixed effects, year fixed effects, and sector average 1998-2000 sales times year fixed effects. Standard errors are clustered at the sector level. *** $\mathrm{p}<0.01,{ }^{* *} \mathrm{p}<0.05$, ${ }^{*} \mathrm{p}<0.1$ 
Table A.5: Descriptive Statistics - Balanced Panel, All Firms

\begin{tabular}{|c|c|c|c|c|c|c|}
\hline & \multicolumn{3}{|c|}{ Balanced Panel } & \multicolumn{3}{|c|}{ All Firms } \\
\hline & (1) & $(2)$ & (3) & (4) & $(5)$ & (6) \\
\hline & $\mathrm{N}$ & Mean & Std. Dev. & $\mathrm{N}$ & Mean & Std. Dev. \\
\hline Non-deductible share 1998-2000 Chinese Data & 180,148 & 0.404 & 0.067 & $1,268,574$ & 0.397 & 0.067 \\
\hline VAT (1000 RMB) & 180,148 & 2043 & 3085 & $1,268,574$ & 1302 & 2568 \\
\hline VAT/Sales & 180,148 & 0.042 & 0.033 & $1,268,574$ & 0.035 & 0.032 \\
\hline TFPR OLS & 180,148 & 4.618 & 0.532 & $1,268,574$ & 4.611 & 0.543 \\
\hline TFPR DLW & 180,148 & 0.278 & 1.540 & $1,268,574$ & 0.175 & 1.366 \\
\hline Sales (1000 RMB) & 180,148 & 58545 & 80044 & $1,268,574$ & 42902 & 73267 \\
\hline Employment (\# workers) & 180,148 & 355 & 511 & $1,268,574$ & 245 & 449 \\
\hline Wage Bill (1000 RMB) & 180,148 & 3848 & 6053 & $1,268,574$ & 2514 & 15610 \\
\hline Deductible Input Share & 180,148 & 0.835 & 0.109 & $1,268,574$ & 0.852 & 0.108 \\
\hline Export Share & 166,076 & 0.134 & 0.276 & $1,136,055$ & 0.093 & 0.238 \\
\hline Imported Input Share & 180,138 & 0.300 & 3.136 & $1,268,504$ & 0.305 & 4.408 \\
\hline State-owned & 180,148 & 0.368 & 0.482 & $1,268,574$ & 0.232 & 0.422 \\
\hline Privately-owned & 180,148 & 0.363 & 0.481 & $1,268,574$ & 0.552 & 0.497 \\
\hline Foreign Owned & 180,148 & 0.268 & 0.443 & $1,268,574$ & 0.214 & 0.410 \\
\hline Corporate taxes & 180,148 & 604 & 1827 & $1,268,574$ & 378 & 1606 \\
\hline
\end{tabular}

Notes: Observations are at the firm and year level. 


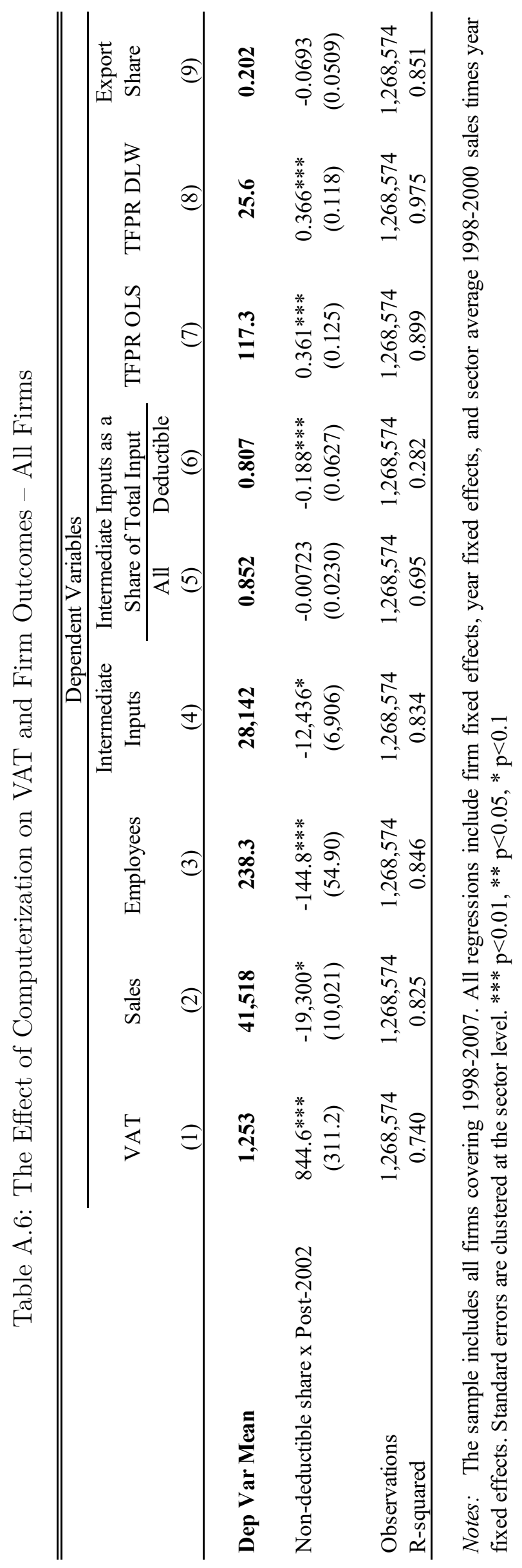




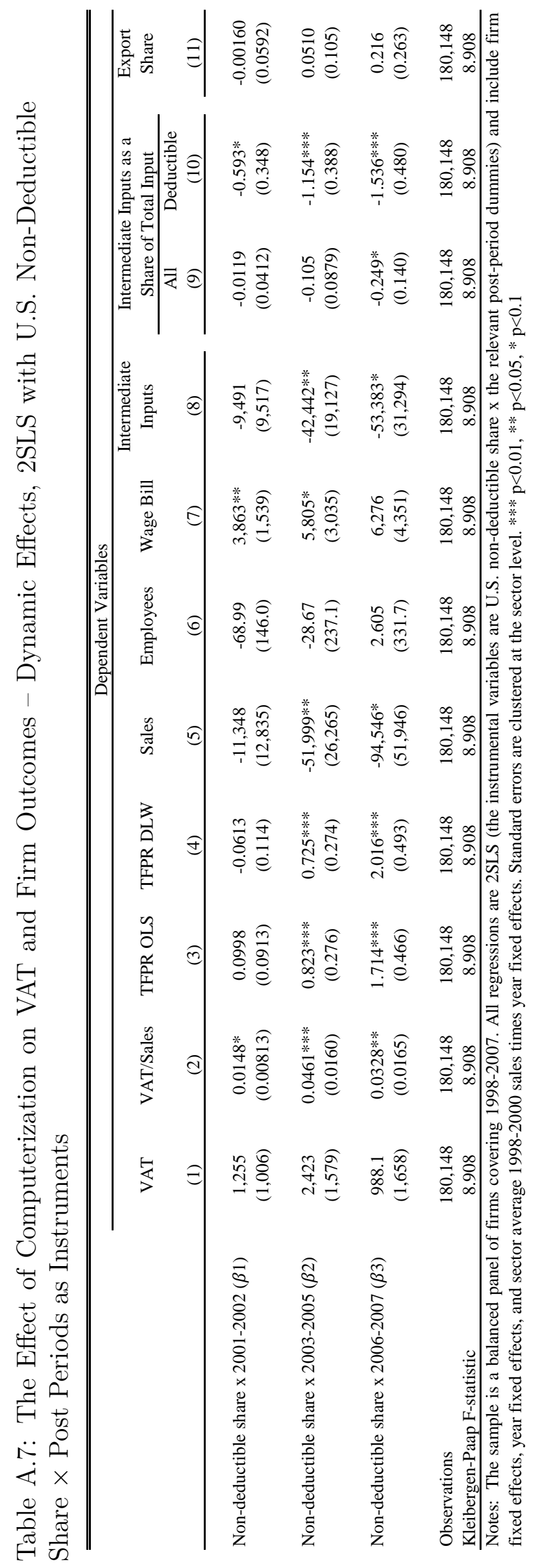




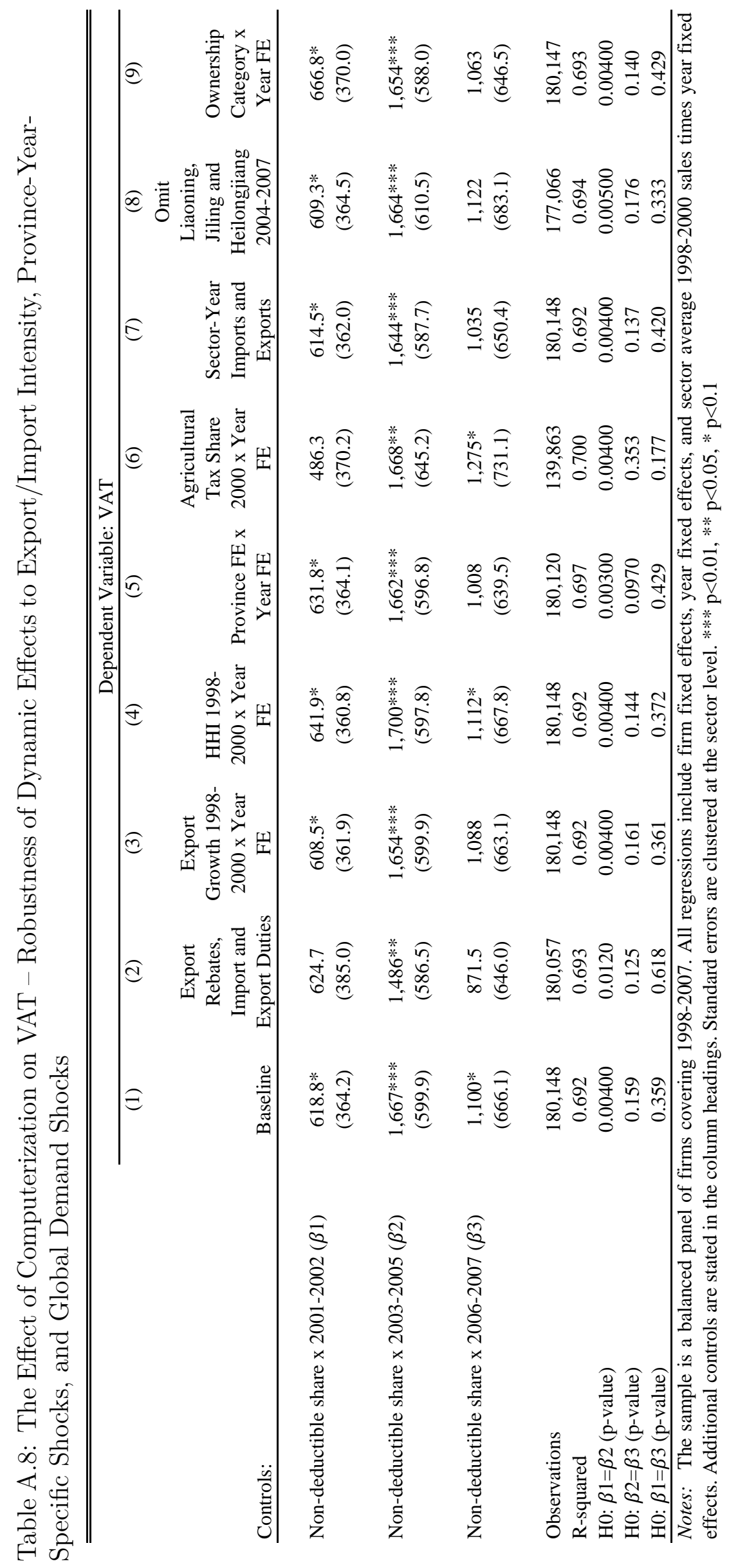


Table A.9: The Effect of Computerization on VAT - Yearly Effects

\begin{tabular}{|c|c|}
\hline \multicolumn{2}{|c|}{ Dependent Variable: VAT } \\
\hline Non-deductible Share x 1998 & $\begin{array}{c}-68.46 \\
(376.7)\end{array}$ \\
\hline Non-deductible Share x 1999 & $\begin{array}{c}183.3 \\
(280.6)\end{array}$ \\
\hline Non-deductible Share x 2000 & $\begin{array}{c}252.6 \\
(237.5)\end{array}$ \\
\hline Non-deductible Share x 2001 & $\begin{array}{l}- \\
-\end{array}$ \\
\hline Non-deductible Share x 2002 & $\begin{array}{c}729.4 * * \\
(364.6)\end{array}$ \\
\hline Non-deductible Share x 2003 & $\begin{array}{c}1,070 * * \\
(524.1)\end{array}$ \\
\hline Non-deductible Share x 2004 & $\begin{array}{c}1,564 * * * \\
(528.6)\end{array}$ \\
\hline Non-deductible Share x 2005 & $\begin{array}{c}1,621 * * * \\
(455.5)\end{array}$ \\
\hline Non-deductible Share x 2006 & $\begin{array}{c}1,209 * * \\
(546.0)\end{array}$ \\
\hline Non-deductible Share x 2007 & $\begin{array}{l}971.9 * \\
(578.6)\end{array}$ \\
\hline Observations & 180,148 \\
\hline R-squared & 0.692 \\
\hline 2002-2007 Joint p-value & 0.00963 \\
\hline
\end{tabular}

Notes: This sample comprises of a balanced panel of firms during 1998-2007. All regressions include firm fixed effects, year fixed effects, and sector average 1998-2000 sales times year fixed effects. The standard errors are clustered at the sector level. ${ }^{* * *} \mathrm{p}<0.01,{ }^{* *} \mathrm{p}<0.05,{ }^{*} \mathrm{p}<0.1$ 
Figure A.1: Tax Personnel, Audit Rates and "Problematic" Cases Over Time

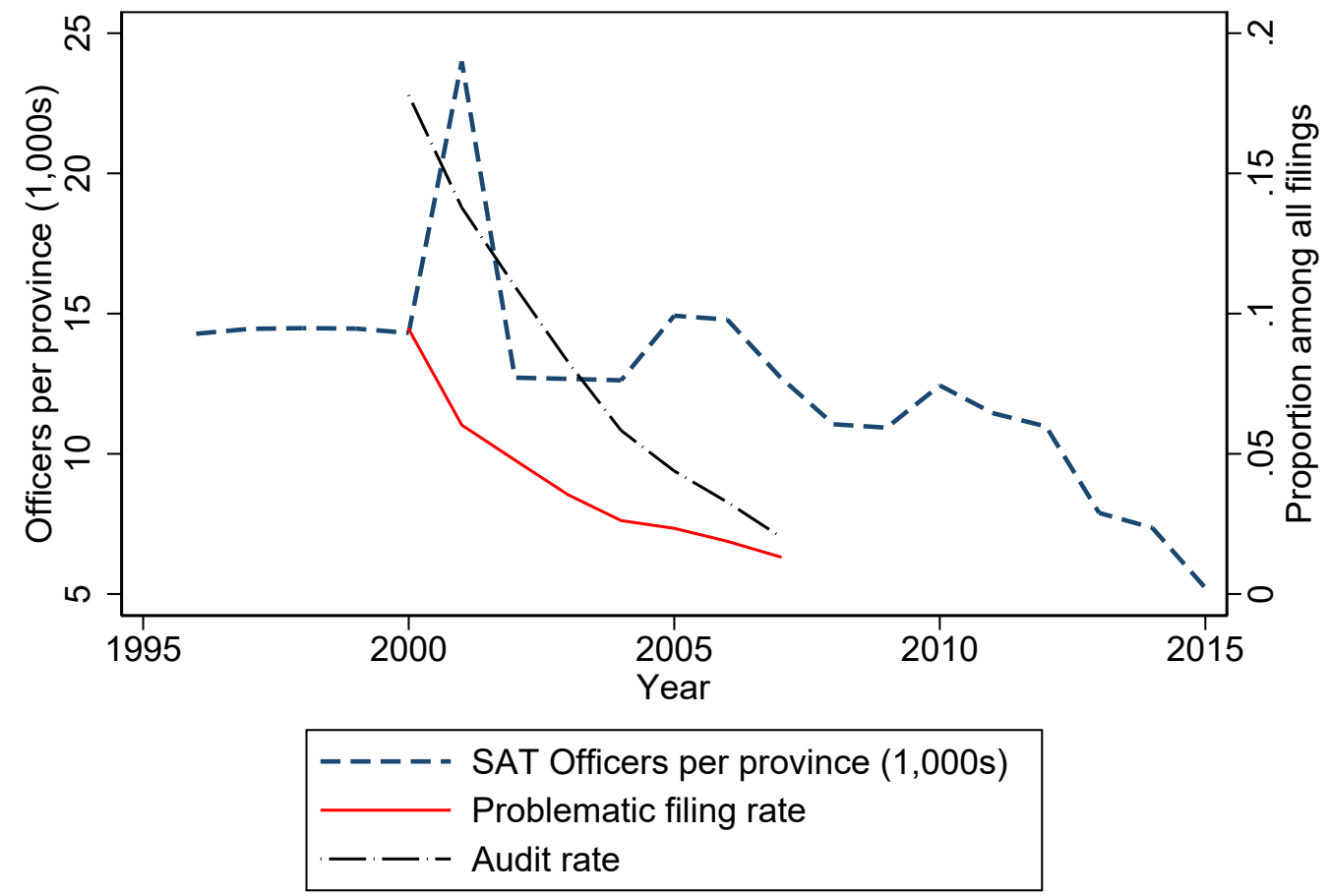

Data: Tax Yearbooks of China and Tax Audit Yearbooks of China 
Figure A.2: VAT Deduction Invoice, Prior to Digital Encryption/Computerization

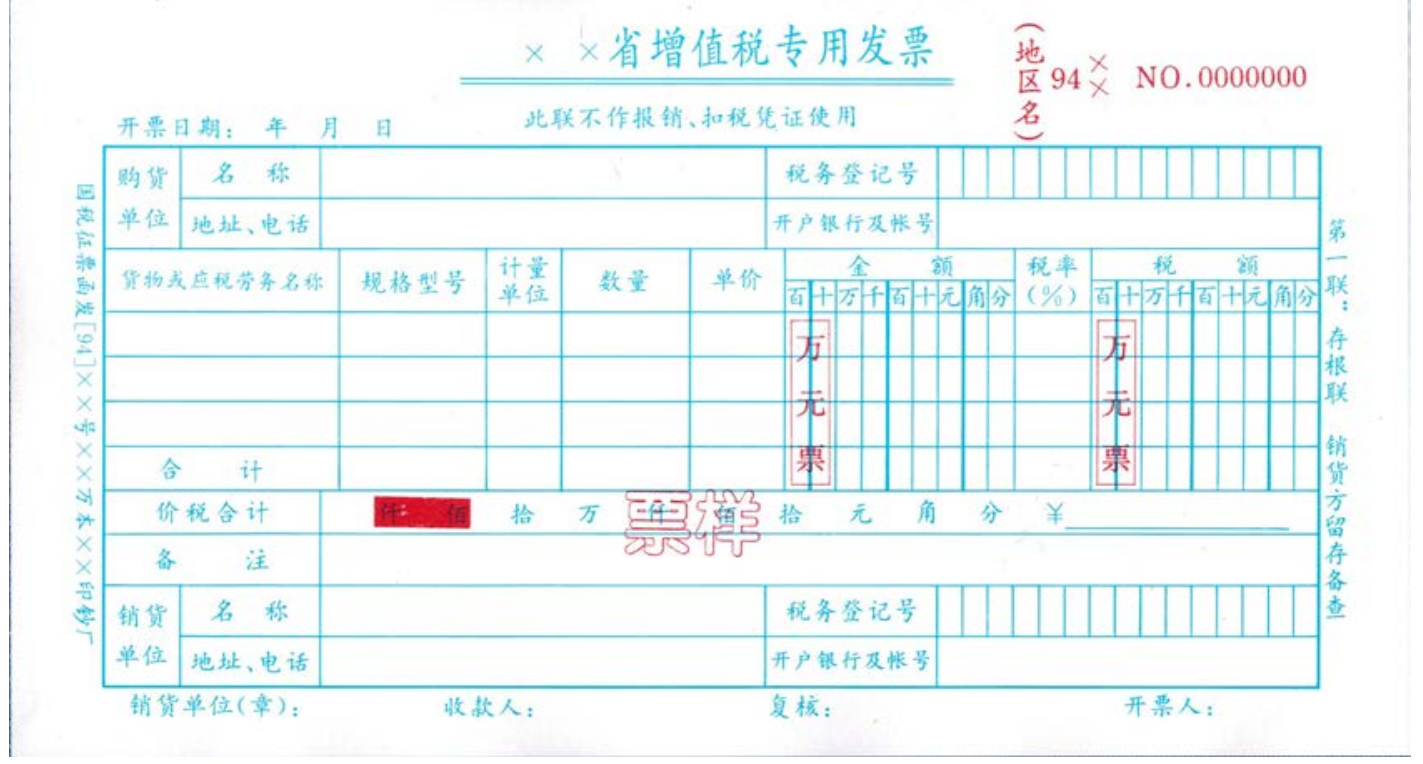

Figure A.3: VAT Deduction Invoice, After Digital Encryption/Computerization

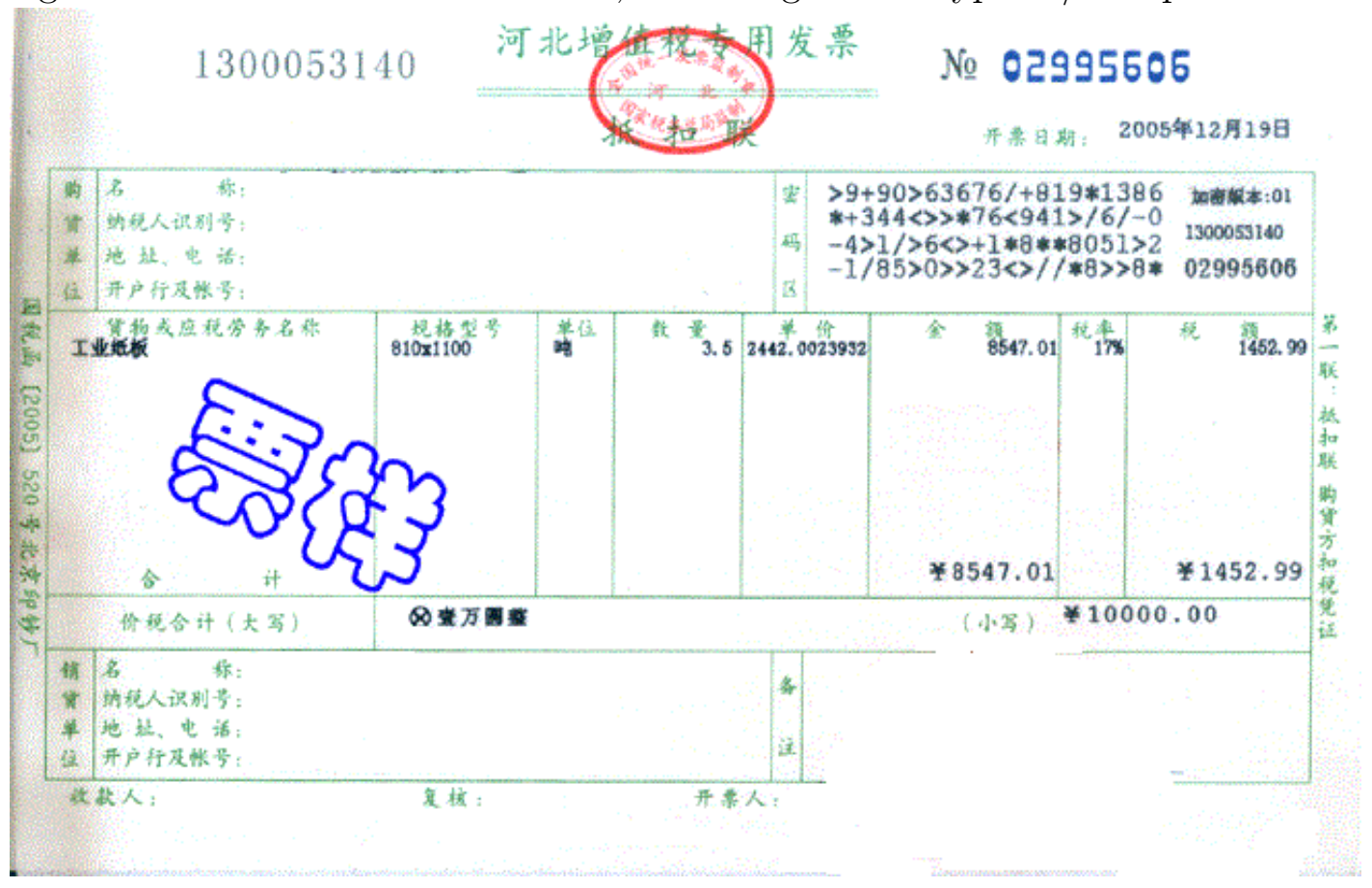

